\title{
Development of Combined Manufacturing Technologies for High-Strength Structural Components
}

\section{Berend Denkena ${ }^{a}$, Bernd Breidenstein ${ }^{b}$, Luis de Leon $^{c}$ and Jan Dege}

Leibniz Universität Hannover, Institute of Production Engineering and Machine Tools,

An der Universität 2, 30823 Garbsen, Germany

\author{
adenkena@ifw.uni-hannover.de, ${ }^{b}$ breidenstein@ifw.uni-hannover.de, 9 leon@ifw.uni-hannover.de, \\ dege@ifw.uni-hannover.de,
}

Keywords: Aluminium alloys, machining, deep rolling, combined processes, simulation, locally modified material properties

\begin{abstract}
Novel manufacturing technologies for high-strength structural components of aluminium allow a local modification of material properties to respond to operational demands. Machining and finishing processes for changing material properties like deep rolling or rubbing are to be combined to a single process step. The intention is the controlled adjustment of the component's properties by the modification of its subsurface. For that purpose the essential understanding of the interaction mechanisms of the basic processes turning, deep rolling and rubbing is necessary. Influences of the tool geometry as well as of the process parameters on the material properties are investigated. The results will be extended by parameter studies within numerical simulations. Thereafter, combinations of the basic processes in process sequences are analyzed to their ability to modify the subsurface properties. In consideration of these results, a prototypic combined turn-rolling tool is developed
\end{abstract}

\section{Introduction}

Aluminium and its alloys are important construction materials for lightweight applications. High strength at low density of selected aluminium alloys enables the construction of a variety of structural and planar components [1,2]. Aluminium parts used in such a way must bear high wear and oscillating mechanical loads during application. In practice the most stressed regions in technical components are often found in the subsurface, e. g. by bending, torsion and corrosion loads. Therefore, the properties of the component's subsurface are of outstanding importance [3, 4]. These properties are considerably influenced by the applied machining procedure. Different states of residual stress, hardness, surface roughness and microstructure can be realized. A controlled influence on the subsurface by the machining process can improve the component's properties and life cycle [5].

Relevant machining processes which are applicable for aluminium components are e. g. milling, drilling and turning. In steel machining process steps for subsurface improvement are added, like deep rolling, finish rolling or shot peening $[6,7]$. Thus, surface near compressive residual stresses are created, which increase fatigue strength, reduce crack propagation and improve wear resistance [8]. Similar effects are found due to deep rolling of Ti6Al4V [9]. This indicates that an overlapping of rolling tracks allows the creation of planar compressive residual stresses in the subsurface of the workpiece. Degree and depth of subsurface influences are mainly determined by workpiece material, tool, process parameters as well as subsurface properties before machining. 
Several studies have shown that for aluminium an improvement of material properties can be achieved by mechanical surface hardening. Due to dynamic tensile/compressive loads surface shot peening of $\mathrm{AlCuMg} 2$ led to an increase of load cycles of one magnitude [10]. Furthermore, it has been shown, that rolled and notched parts bear up to 100 times more load cycles than peened parts, especially at high stress amplitudes of $\sigma=500 \mathrm{MPa}$. This can be explained by plastic deformation effects in the subsurface. Also for the die cast material GD-AlSi8Cu3 a significant increase of the load cycles by peening after milling was shown [11]. The surface treatment procedure inhibits crack formation and propagation by shutting surface near shrink holes and pores by strengthening the component's subsurface. The importance of single alloying constituents for subsurface properties is rarely examined. Peening of AlMg3 with dry ice is a possibility of reducing the surface roughness and improving the residual stress state [12]. Overall aluminium and its alloys offer a good potential for improving material properties by the modification of component subsurfaces.

\section{Subsurface modification of aluminium alloys by mechanical surface hardening}

Commonly applied methods for mechanical surface hardening of aluminium alloys are deep rolling and finish rolling [13]. Current tools use a hydrostatic unit, to realize a pressure load by one or more balls on the workpiece's surface [14]. Subsurface properties are mainly influenced by rolling speed, rolling force, i.e. hydrostatic pressure, rolling feed and initial material hardness [15].

A higher number of rolling cycles on a surface element results in an increase of hardness and residual compressive stress [16]. Increasing rolling speed causes reduced hardness increase, less roundness of rotation-symmetric parts and higher surface roughness [17]. Further increase of the rolling speed can lead to a neutralization of compressive residual stress. The reason for this effect is not completely understood so far.

Besides, also rolling force and feed influence the component's subsurface. High forces cause increased plastic yielding and cold deformation, which smoothes the existing surface profile to a lower level and increases hardness explicitly [18]. Additionally, the compressive residual stress level is increased by higher rolling forces.

Higher rolling forces considerably improve fatigue strength of $\mathrm{AlCuMg} 2$ [19]. An increase of the load cycles by a factor of 100 up to $\mathrm{N}_{\mathrm{f}}>106$ at a rolling force of $\mathrm{F}_{\mathrm{R}} \approx 800 \mathrm{~N}$ is achieved. This is attributed to increased residual compressive stress in the subsurface of the component. Rolling of boreholes in 8090 aluminium caused remarkable compressive residual stress [20]. This influence showed a depth effect of several millimeters. There is an interdependency of rolling force and residence time. Depending on residence time hardness increase of rotation-symmetric parts up to $120 \%$ could be achieved by high rolling force at short residence time [17].

The initial hardness of the workpiece material also plays an important role for strengthening. Complex dependences of residence time, rolling force, rolling speed and initial hardness for $\mathrm{AlCuSiMn}$ are reported [16]. By this increases of up to $90 \%$ from the initial hardness were possible. But also contradictory results have been obtained. For $\mathrm{AlCu}$ it was found that higher initial hardness leads to reduced hardness increase [21].

\section{Machining and hardening of lightweight alloys}

In a study comparing aluminium AlMgSil and Magnesium AZ91 HP it was found that both materials generally can be machined easily. When turning magnesium, material adhesion at the tool flank face is observed. This can be eliminated successfully by the use of PCD tools. Dry machining leads to good results of surface quality. Uncoated as well as TiN-coated carbide tools should be used at cutting speeds of $\mathrm{v}_{\mathrm{c}}>600 \mathrm{~m} / \mathrm{min}$ only with cooling lubricant. The use of cooling lubricants and PCD tools allows cutting speeds of $\mathrm{v}_{\mathrm{c}}>2000 \mathrm{~m} / \mathrm{min}$ for the magnesium material [22].

Machining of aluminium requires higher cutting forces than machining of magnesium. This is a result of the higher material strength. At low cutting speeds slightly better surface qualities than for 
magnesium are achievable. PCD as cutting material generally requires lower cutting forces and generates a better surface roughness than carbide tools.

Further investigations concerning the machining of aluminium alloys e. g. showed that for high performance drilling and rubbing as well as circular machining of $\mathrm{AlZn} 6 \mathrm{MgCu}$ a significant reduction of process time could be achieved by the application of finely tuned process parameters, without deterioration of the process results [23, 24]. The potentials of high performance cutting can be opened up additionally by the use of coated carbide tools. Investigations showed that CVD and PVD coated carbide drills are advantageous concerning cutting forces, burr and built-up edge formation when machining AlSi9Cu3 [25].

Besides, there is further knowledge about the influence of the residual stress state in the subsurface of aluminium. Cutting of AlCuMg2 influences the subsurface by a depth of $\mathrm{z}_{\max } \approx 120 \mu \mathrm{m}$. The maximum compressive residual stress of $\sigma=-120 \mathrm{MPa}$ is found in a depth of $\mathrm{z}=20 \mu \mathrm{m}$. At greater depths the compressive residual stress is reduced and a change to tensile residual stress is observed. The residual stress profile significantly depends on the cutting material. Carbide tools effect up to four times higher residual tensile stress values (max. $\sigma=170 \mathrm{MPa}$ at $\mathrm{v}_{\mathrm{c}}=500 \mathrm{~m} / \mathrm{min}$ ) than PCD tools. No definite influences of depth of cut and cutting speed were found.

Investigations concerning mechanical surface hardening of an AZ91 magnesium alloy proved deep and finish rolling to be suitable procedures. Increase of rolling force and speed led to improved surface roughness with $\mathrm{Rz}<5 \mu \mathrm{m}$ as well as to an increase of hardness of up to $30 \%$ [22]. Current results of deep rolling of magnesium AM50 showed that already machining processes cause a high level of residual compressive stress. In a depth of $z=50-150 \mu \mathrm{m}$ below the surface it changes to tensile stress. Deep rolling creates residual compressive stress up to a depth of $z=600 \mu \mathrm{m}$. At rolling pressures $\mathrm{p}_{\mathrm{r}}>6 \mathrm{MPa}$ the level of the achievable residual compressive stress decreases again (Fig. 1). The reason for decreasing residual compressive stress can be explained by a significant decrease of the yield stress at increasing deformation degrees $(\phi \geq 0.15)$ [26].

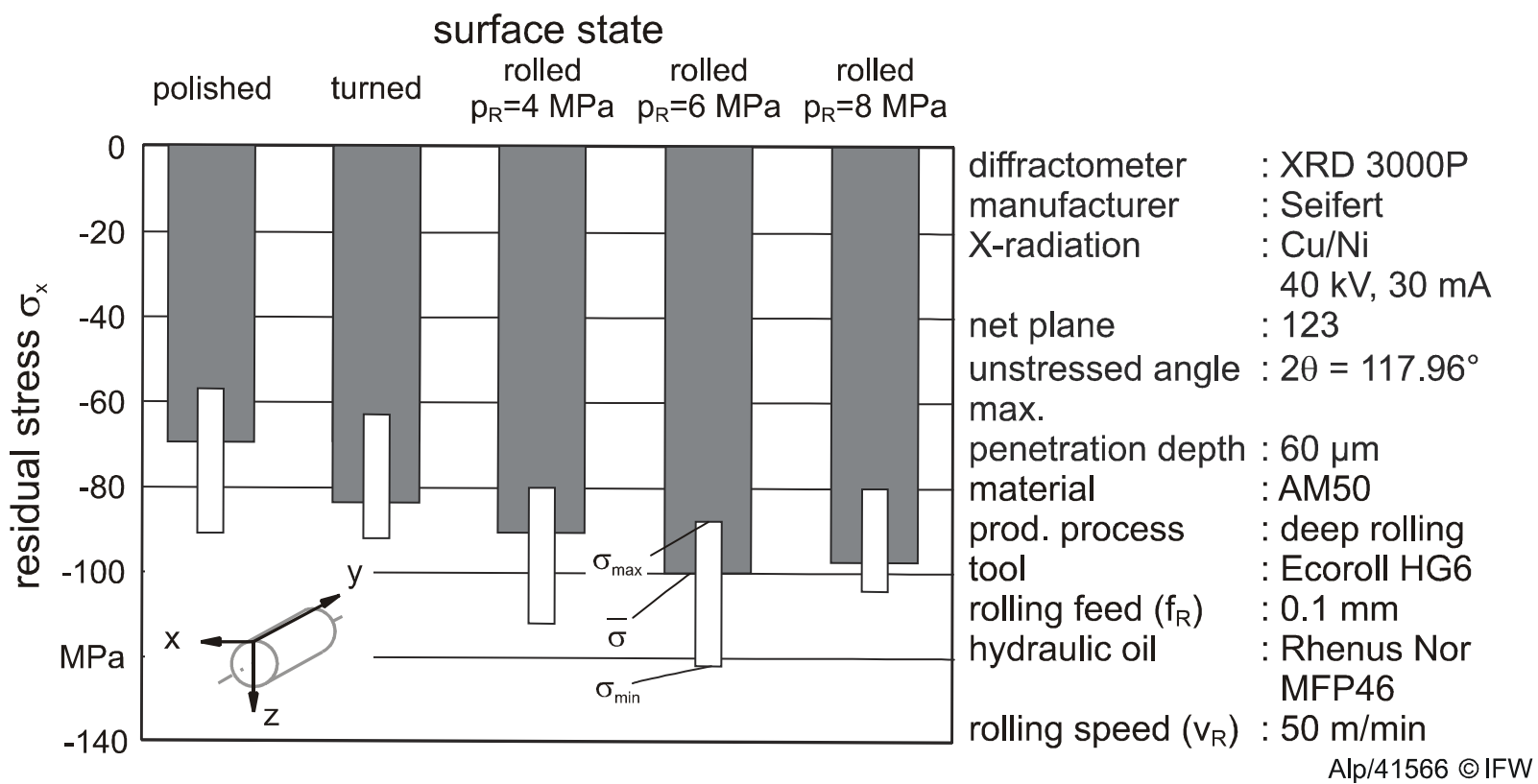

Fig. 1: Compressive residual stress for different surface finishes of magnesium AM50 


\section{Goals of the presented project}

The vision of the presented project is the development of new manufacturing techniques for complete machining of high-strength structural parts of aluminium with a local adaptation of component properties to exterior load demands. The main aim of the project is a combination of the manufacturing processes "material separation" and "modification of material properties" to one single process step. During the research project the depth effect of the subsurface influence is to be increased stepwise by the development and adaptation of the manufacturing technology. This will prospectively allow to reduce the application of riveted joints, applied in aircraft construction, as well as the accompanying component attenuation and the manufacturing complexity. The methods to be developed contain the potential to strengthen a component's subsurface from few micrometers to several millimeters depth systematically. Thus, according to the demands, an increased resistance of the components against dynamic and tribological loads is achieved. Fig. 2 shows the methodology of the project for its complete duration over 12 years.

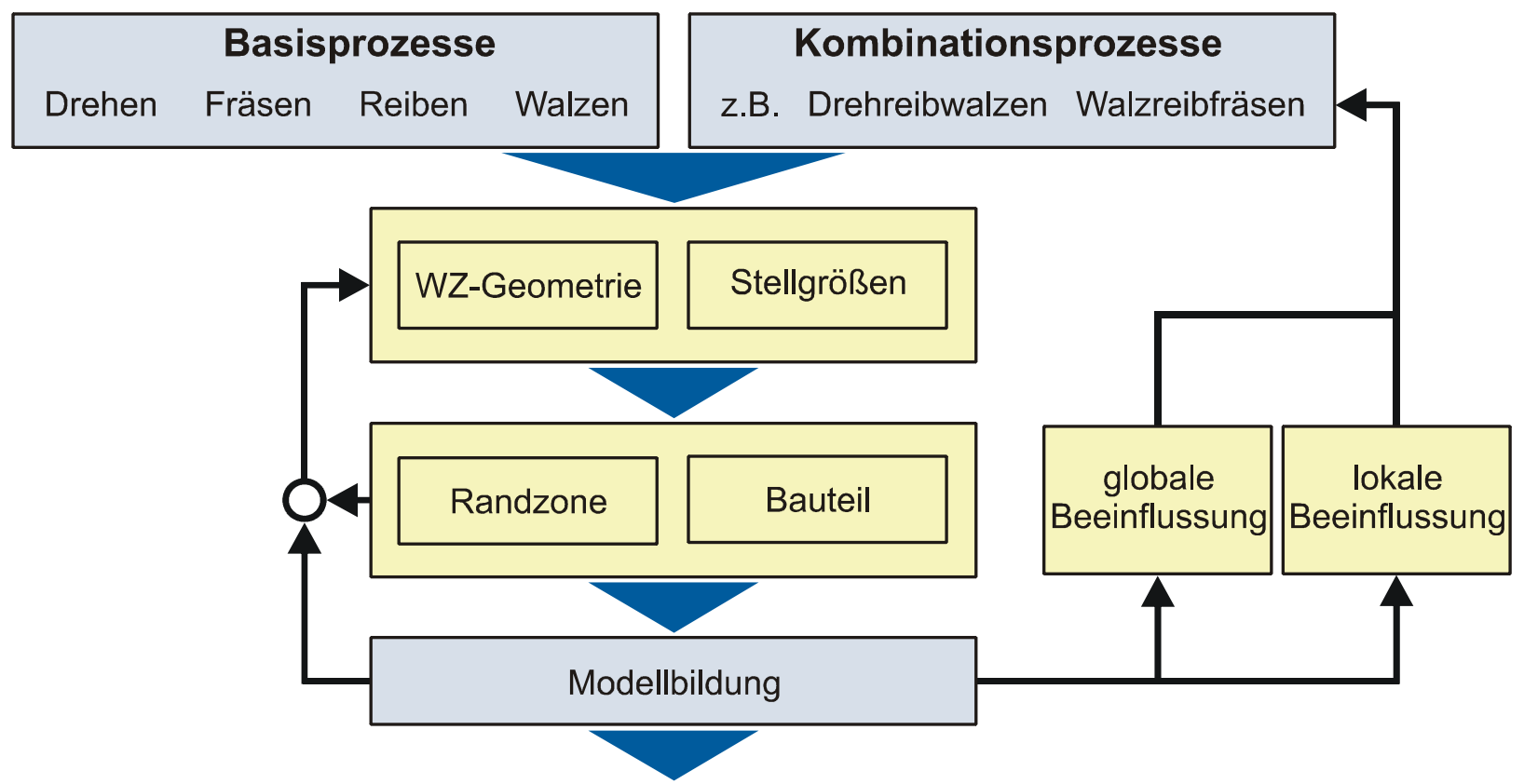

Gezielte Steuerung der Randzonen- und Bauteileigenschaften

Fig. 2: Methodology of the project for the duration of 12 years

My/42911 @ IFW

The fundament of the combined processes is a systematic approach, which is based upon the knowledge of the basic processes. For that purpose the influences of tool geometry and process parameters on subsurface and workpiece properties for turning, milling, rubbing and rolling have to be determined. Modeling of the essential processes and mechanisms is the core element of the research project and is verified by means of numerical simulations. From the vision of the functional principles different combined processes are possible, e. g. "turn-rub-rolling" or "roll-rubmilling". Fig. 3 shows exemplarily the functional principle of a turn-rub-rolling process.

The coupling of processes is expected to enable more intensive mechanical effects concerning residual stress and strengthening of the subsurface compared to single processes. A systematic control of the combined process, e. g. by retarding and thus slipping of the rolling ball, allows not only a further improvement of subsurface properties, but also a sectional local modification of the workpiece. The final subsurface characteristics are significantly determined by the interdependencies of the processes. Exact knowledge of the single processes and their interdependencies are prerequisites for the planning of defined and when indicated controlled combined processes and for the determination of their exact effects and limits. 

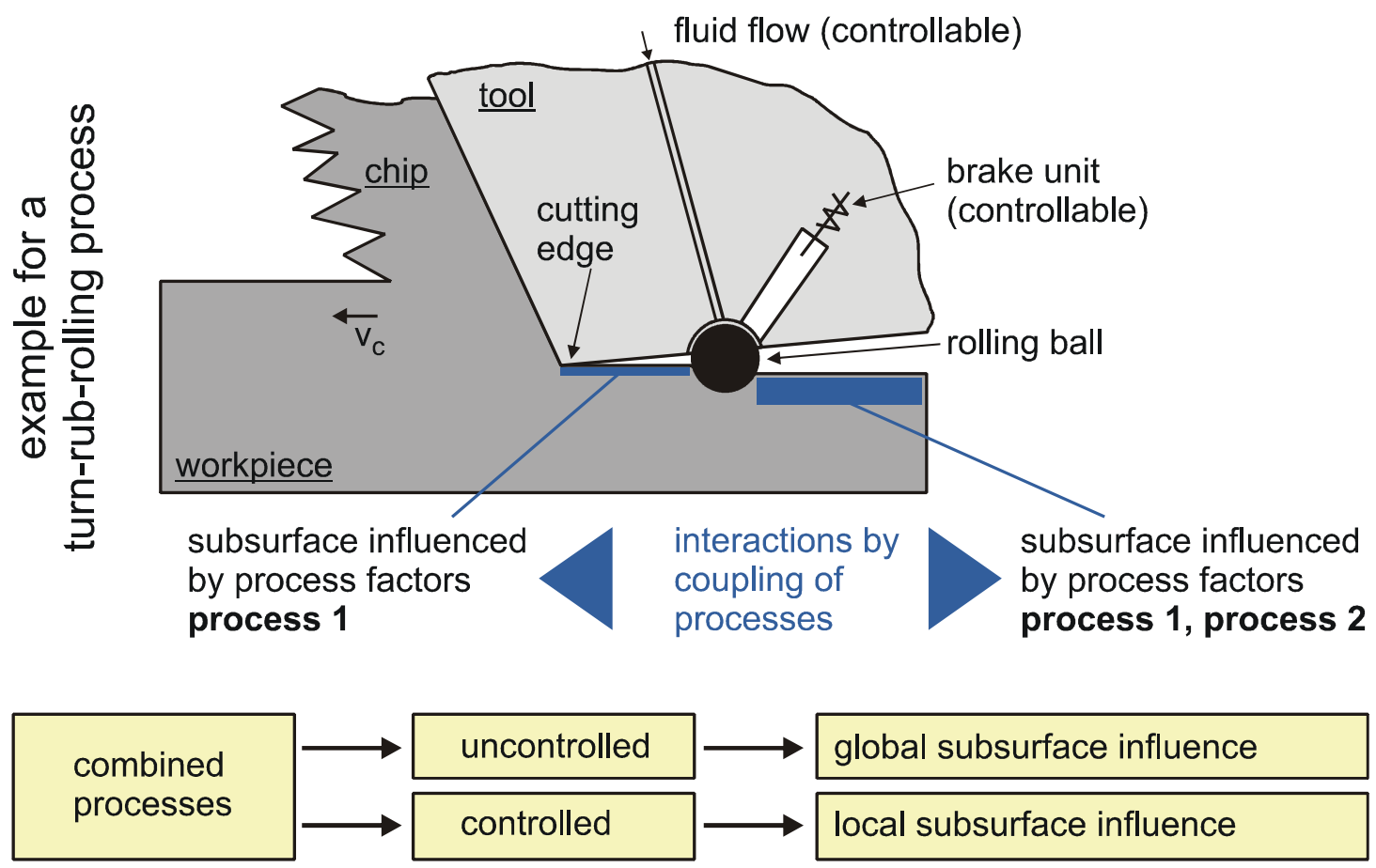

Bon/43218 ㄷIFW

Fig. 3: Vision and functional principle of a turn-rub-rolling process

Principal object of this project for the first period of four years is the elementary understanding of the functional mechanisms for combined machining and the development of methods for the systematically controlled generation of subsurface properties (Fig. 4). This will be tested experimentally and verified by numerical FE-models and implemented by means of a prototypic combination tool.

\section{goal: $\quad$ essential understanding of combined machining and method development for the systematic control of subsurface and workpiece properties by process and tool characteristics}

Fig. 4: Project goals for the first period

My/42912 @ IFW

Besides the main goal the project includes three sub-goals. They comprise at first knowledge about influencing effects of the single processes on the subsurface under variation of process factors. This allows the determination of limiting conditions and crucial variables as well as functional mechanisms. This is inevitable for the analysis of the spatial and the temporal interaction of 
processes and their interdependencies, which is necessary to develop possibilities of controlling for combined turning tools, e. g. for turn-rolling or turn-rub-rolling.

During the second period analyses of the basic process "milling" will follow, as well as a transfer of obtained results to a combined milling process. Process and tools will be developed for discontinuous cutting. Another element of the second period will be the proof of advanced component properties by the application of combined production processes with a focus on process limits, regarding fatigue strength and crack formation. With this extension of so far obtained conclusions it will be possible to create a model for basic mechanisms and functional interrelations of subsurface manipulation by combined milling.

The newly developed processes demand further requirements for the machine tools. This concerns the static and dynamic stiffness of the machine construction, as well as the design of the workspace of the machine. This requires the use of a machine tool during the second period, whose requirements are defined by the experience gained during the first period.

Furthermore, an advancement of the combined manufacturing technology is planned. By milling macroscopically structured component surfaces are to be formed to their final shape by rolling and plastic deformation. Thus a higher grade of local subsurface strengthening is to be reached as well as a systematic crack deviation.

\section{Future Applications}

Manifold applications for components with locally adapted material properties are possible. Prominent applications are aircraft constructions. Aircrafts are built by the use of different structured and plane elements, which are riveted to each other. At especially stressed positions, e. g. around doors and windows, additional sheets are riveted in order to prevent crack propagation (Fig. 5 , present).

present

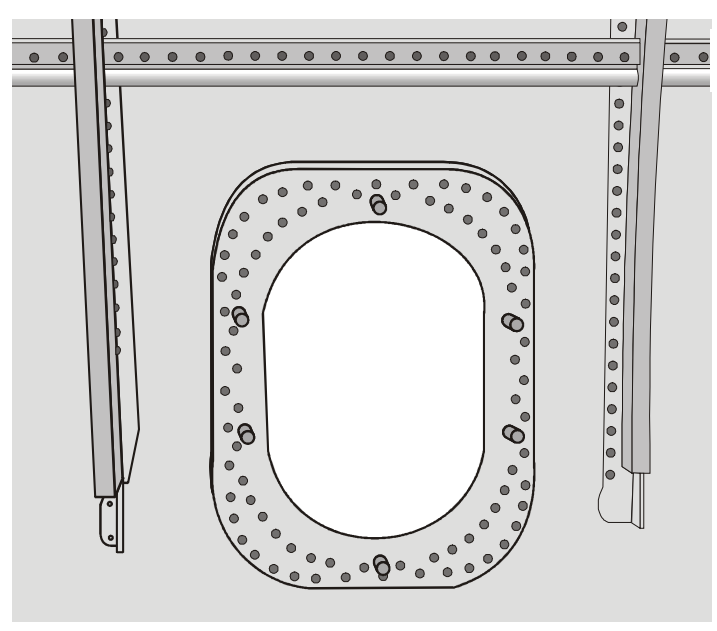

stringer, frames, additional sheet, riveted foresight

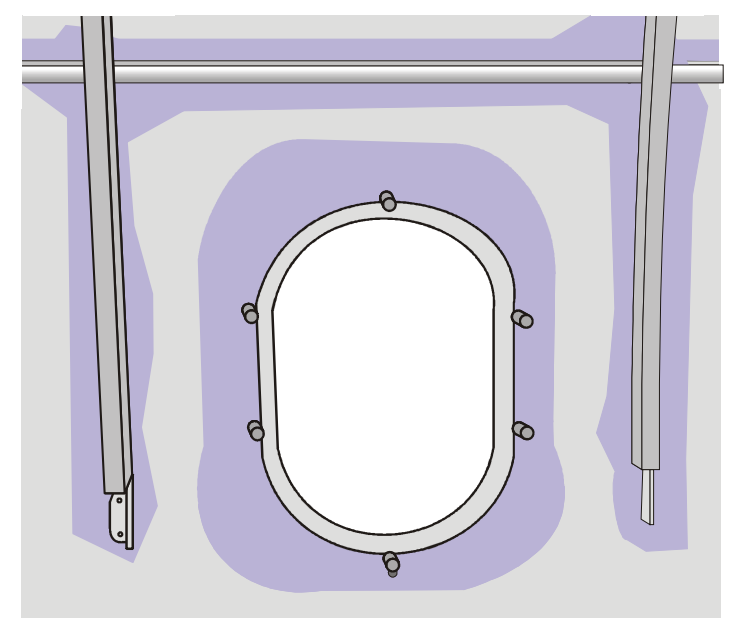

pre-joint framework, welded, locally adapted properties

Bre/43191 @ IFW

Fig. 5: Replacement of rivetings in aircraft construction

With the new combined manufacturing technologies it will be possible in future to reduce or even replace the rivetings by pre-joining frameworks, which will be completely machined. During the process a local adaption of component properties will be possible (Fig. 5, future). 


\section{Applied Methods}

The following methods have been used to implement the work packages within the frame of the first period of the research project:

- Experimental investigation of basic machining processes

- Subsurface zone analyses

- Simulation of the subsurface zone modification using the finite elements method

\section{Method I: Experimental investigation of basic machining/hardening processes}

The cutting tests have been implemented on a Gildemeister CTX520 turning center with linear direct drives using varied parameters. The machining center has a maximum spindle speed of $\mathrm{n}_{\max }=10.0001 / \mathrm{min}$ and a power output of $\mathrm{P}_{\max }=145 \mathrm{~kW}$ (Fig. 6). The workpieces are clamped between centers. The process forces are measured by a Kistler three-component dynamometer of the type 9121 . The forces are represented by the cutting force, the feed force and the passive force.

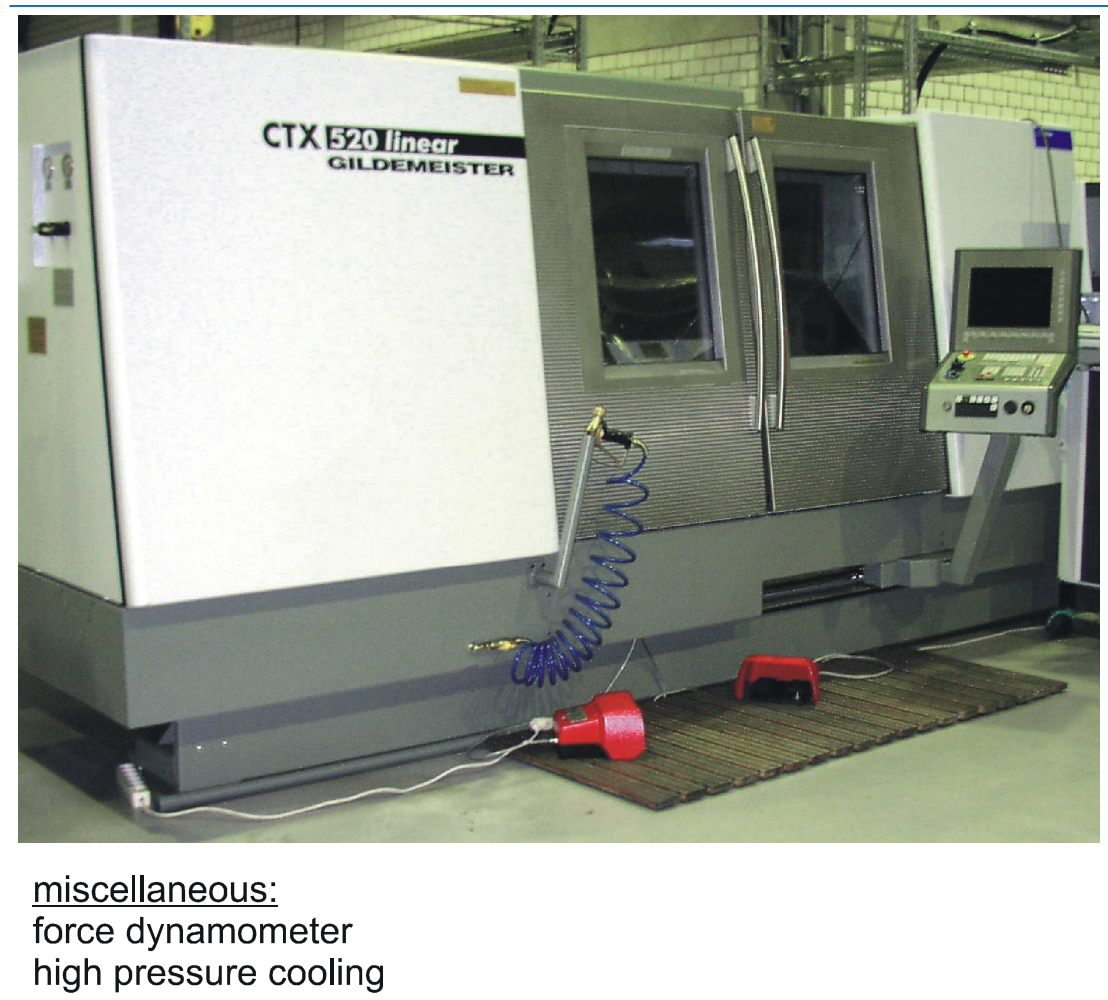

working space:

max. workpiece dia.: $440 \mathrm{~mm}$

max. workpiece length: $1300 \mathrm{~mm}$

Spindle:

nom. power: $145 \mathrm{~kW}$ (S6)

nom. torque: $400 \mathrm{Nm}$

max. speed: $10.0001 / \mathrm{min}$

tooling system:

Sauter turret

number of tools: 12

tool holder: VDI 40

propelled tools:

number of tools: 12

nom. power: $4,5 \mathrm{~kW}$

max. speed: $4.5001 / \mathrm{min}$

numerical control:

Siemens 840 D

ShopTurn

high pressure cooling

Dg/59275 @ IFW

Fig. 6: Turning center Gildemeister CTX520 linear

Because of its high thermal emission coefficient, aluminium can only be subject to thermographic measurement within certain limits. Therefore, the temperatures of the carbide tool in the machining tests are measured by means of a two color pyrometer of the type Impac IP 140. Therefore, a blind hole of about $1 \mathrm{~mm}$ from the rake face is machined into the back of the tool by means of laser ablation. For the temperature measurement, a fiber optic cable is installed in this blind hole and is connected with the pyrometer.

\section{Method II: Subsurface zone analyses}

The surface roughness of the aluminium specimens are measured by means of a Mahr contact stylus. The probe tip has a standardized geometry with a radius of $r=2 \mu \mathrm{m}$ and a point angle of $\alpha=90^{\circ}$. Roughness and waviness are distinguished by filtering, and the critical wavelength is determined depending on the measured surface (DIN EN ISO 4288). A measuring track of $1_{t}=1.75 \mathrm{~mm}$ has been used in the investigations. 
The hardness has been determined by means of Brinell hardness tests. The diameter of the carbide ball was $\mathrm{D}_{\mathrm{K}}=2.5 \mathrm{~mm}$, the test load was $\mathrm{m}_{\mathrm{p}}=62.5 \mathrm{~kg}$.

The residual stresses have been measured by X-ray diffraction using the $\sin ^{2} \psi$-method. An XRD 3000 TT Bragg-Brentano diffractometer of the company GE Sensing and Inspection Technologies has been used, which is equipped with a Cr-tube and a Hecus PSD 50M position sensitive detector (Fig. 7). The reference angle for the measurement of the residual stresses is $2 \theta_{0}=139.31^{\circ}$ (lattice plane $\mathrm{Al} \mathrm{311).} \mathrm{For} \mathrm{determining} \mathrm{the} \mathrm{residual} \mathrm{stress} \mathrm{depth} \mathrm{distribution,} \mathrm{material}$ is removed gradually by electropolishing and further $\sin ^{2} \psi$-measurements are conducted.

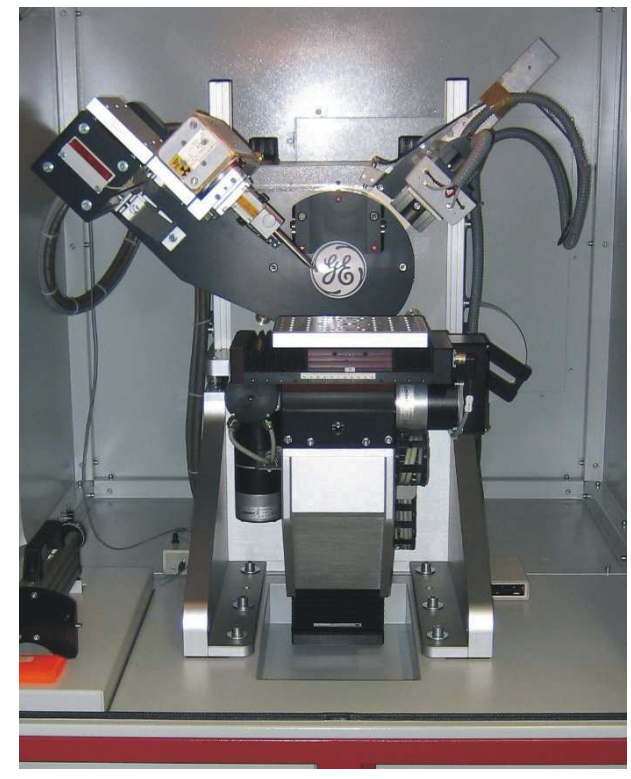

source: GE Inspection Technologies

\author{
technical data: \\ sensor type: \\ goniometer: \\ measurerment range $2 \theta$ : \\ resolution: \\ radius: \\ x-ray power: \\ voltage: \\ current: \\ power: \\ measuring accuracy: \\ specimen size: \\ specimen weight: \\ measurement range: \\ lateral \\ vertical \\ resolution: \\ lateral \\ vertical
}

\author{
multichanneldetector \\ $12^{\circ} 4096$ channel \\ $0-165^{\circ}$ \\ $0.0005^{\circ}$ \\ $170-300 \mathrm{~mm}$ \\ 2-60 kV \\ 2-80 mA \\ $\max .3 .5 \mathrm{~kW}$ \\ $\pm 10 \mathrm{Mpa}$ \\ $600 \times 600 \times 150 \mathrm{~mm}^{3}$ \\ $50 \mathrm{~kg}$ \\ $100 \times 100 \mathrm{~mm}^{2}$ \\ $150 \mathrm{~mm}$ \\ $1 \mu \mathrm{m}$ \\ $1 \mu \mathrm{m}$
}

Fig. 7: XRD 3000 TT X-Ray Diffractometer

\section{Method III: FEM simulation of the subsurface zone modification}

The subsurface zone modification is simulated by means of the finite elements method (FEM). For this, the workpiece is divided into an arbitrary number of separate elements. Following, basis functions are defined for these elements. These functions and the determined boundary conditions form the system of equations which has to be solved. To limit the computing time, the simulation is reduced to two dimensions. The process is reproduced by means of the software Deform-2D by Scientific Forming Technologies Corporation. This simulation software has been developed for the two-dimensional calculation of material flow. It is assumed that the tool is ideally rigid and that the working material is elasto-plastic. Fig. 8 shows the applied material law from the DEFORM database. The model covers the material behavior in the temperature range between $\mathrm{T}=0^{\circ} \mathrm{C}$ to $\mathrm{T}=600^{\circ} \mathrm{C}$ and in the true plastic elongation between 0 to 5 for strain velocities and between $\varepsilon=0-100.000 \mathrm{~s}^{-1}$. The model shows only a low dependency of the strain velocity. 

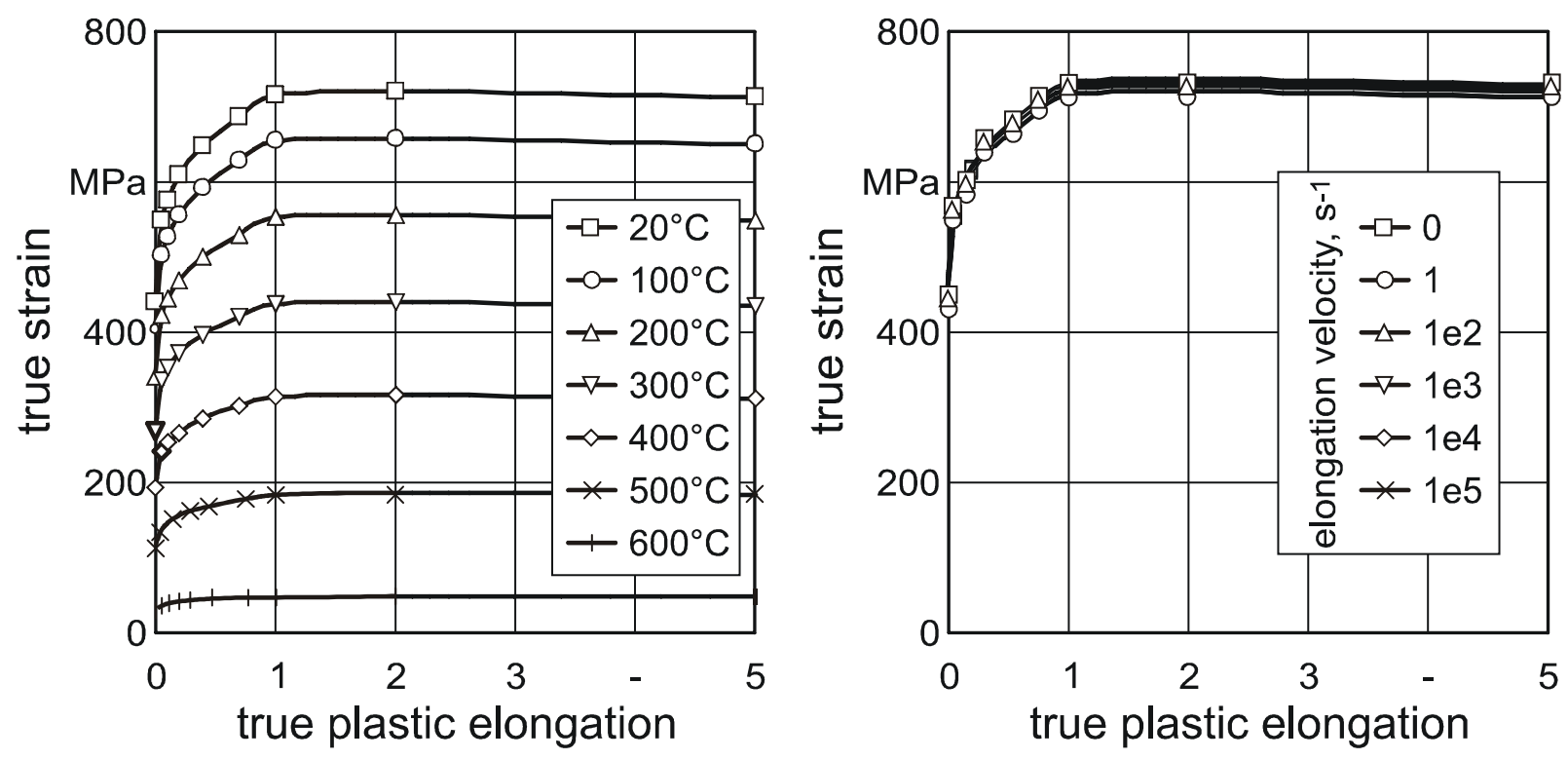

\section{material: Al7075-T6 elasto-plastic}

simulation: Deform2D
Young's modul: $68.900 \mathrm{MPa}$ poisson ratio: 0.3 thermal expansion coefficient: $2.2 \mathrm{e}-6 \mathrm{~W} / \mathrm{m} / \mathrm{K}$ thermal conductivity: $120.2 \mathrm{~W} / \mathrm{m} / \mathrm{K}$ thermal capacity: $2.4336 \mathrm{~J} / \mathrm{kg} / \mathrm{K}$

Dy/51678 @ IFW

Fig. 8: Material law for A17075-T6

For the reproduction of the combined process, the kinematic boundary conditions have to be defined separately. The simulation has first been conducted for the single separate processes of orthogonal turning and rubbing.

\section{FEM Simulation of Orthogonal Turning}

For the FE-Model of the orthogonal turning the tool is modeled with $n=776$ elements and the workpiece with $n=1000$ - 4000 elements. The number of elements of the workpiece varies during the simulation process due to re-meshing procedures. The elements on the workpiece surface and the shear zone are always three times smaller in comparison to the rest of the workpiece. The measured process forces show a good correlation to the simulated forces.

\section{FEM Simulation of Orthogonal Rubbing}

The model of the orthogonal rubbing process consists of $n=732$ elements within the tool and $\mathrm{n}=3000-9000$ elements within the workpiece. Comparable to the orthogonal turning an adaptive mesh has been used to enhance prediction quality of the simulation. Simulations with different feeds and rake angles showed that a combination of a rubbing feed $f_{r}=0.01 \mathrm{~mm}$ with a negative rake angle of $\gamma=-75^{\circ}$ leads to a compression of workpiece material in front of the cutting edge without material removal. These values have been also used for the experimental investigations.

\section{Simulation of Deep Rolling}

The simulation of the deep rolling process with a rolling ball under consideration of the kinematic boundary conditions leads to an accumulation of material in front of the rolling ball. This causes continually increasing process forces and thus avoids a stabilization of the process during the simulation. 
Hence the deep rolling process is simulated via an analogous model. This model uses a cylinder instead of a ball which is pressed with an equivalent force $F_{\text {eqiv }}$ to the workpiece surface (Fig. 9).

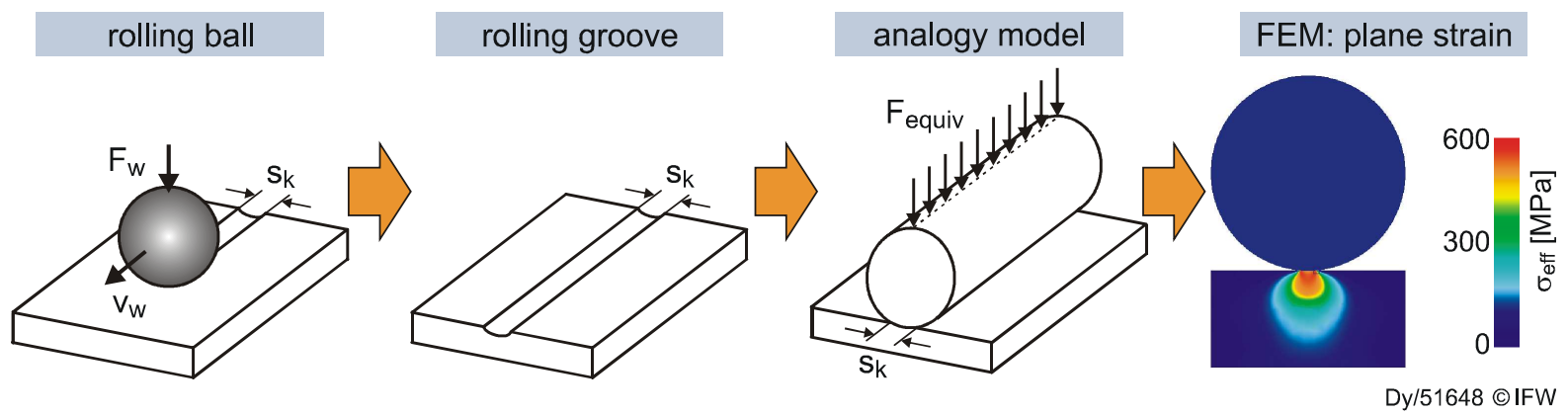

Fig. 9: Analogy model of the deep rolling process

The equivalent force is identified by the experimental determination of the interrelationship between rolling force $F_{w}$ and width of the groove left by the rolling ball $s_{k}$. Thereafter, the 2DFEM-model is used to identify an equivalent rolling force $F_{\text {equiv }}$ which causes the same groove width $s_{\mathrm{k}}$. The equivalent force is based on several experimentally measured rolling force / groove width combinations. A rolling force of $F_{r}=300 \mathrm{~N}$ causes a groove width of $s_{k}=0.7 \mathrm{~mm}$, which equals an equivalent rolling force of $\mathrm{F}_{\text {equiv }}=880 \mathrm{~N}$ for the simulation (Fig. 10).
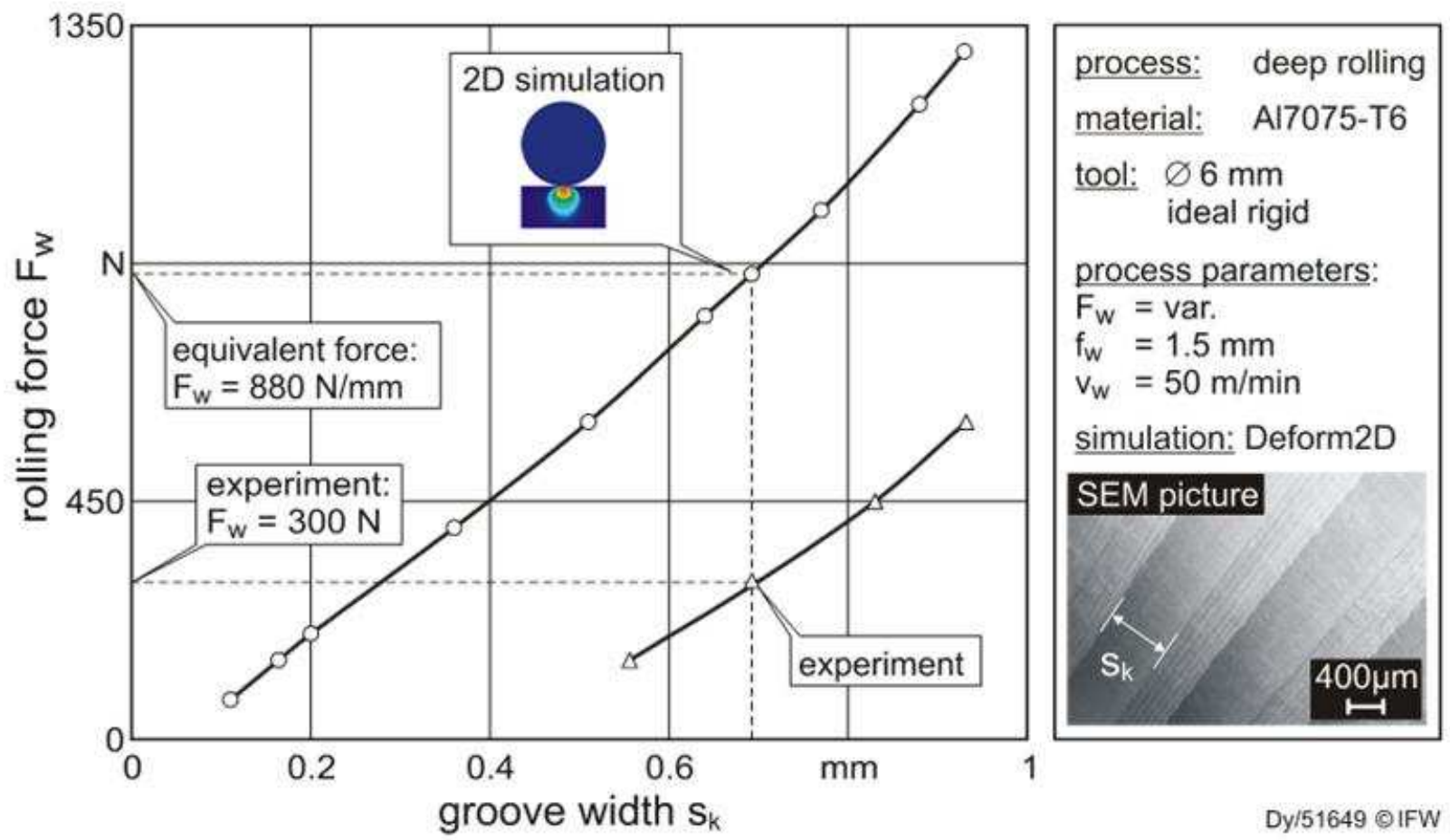

Fig. 10: Calculation of the equivalent force

To predict the residual stresses in the workpiece subsurface caused by the deep rolling process, the cylinder from the analogous model is duplicated. An amount of duplicates, corresponding to the number of rolling grooves, are pressed on the workpiece surface with a distance of $d=f_{w}$. 

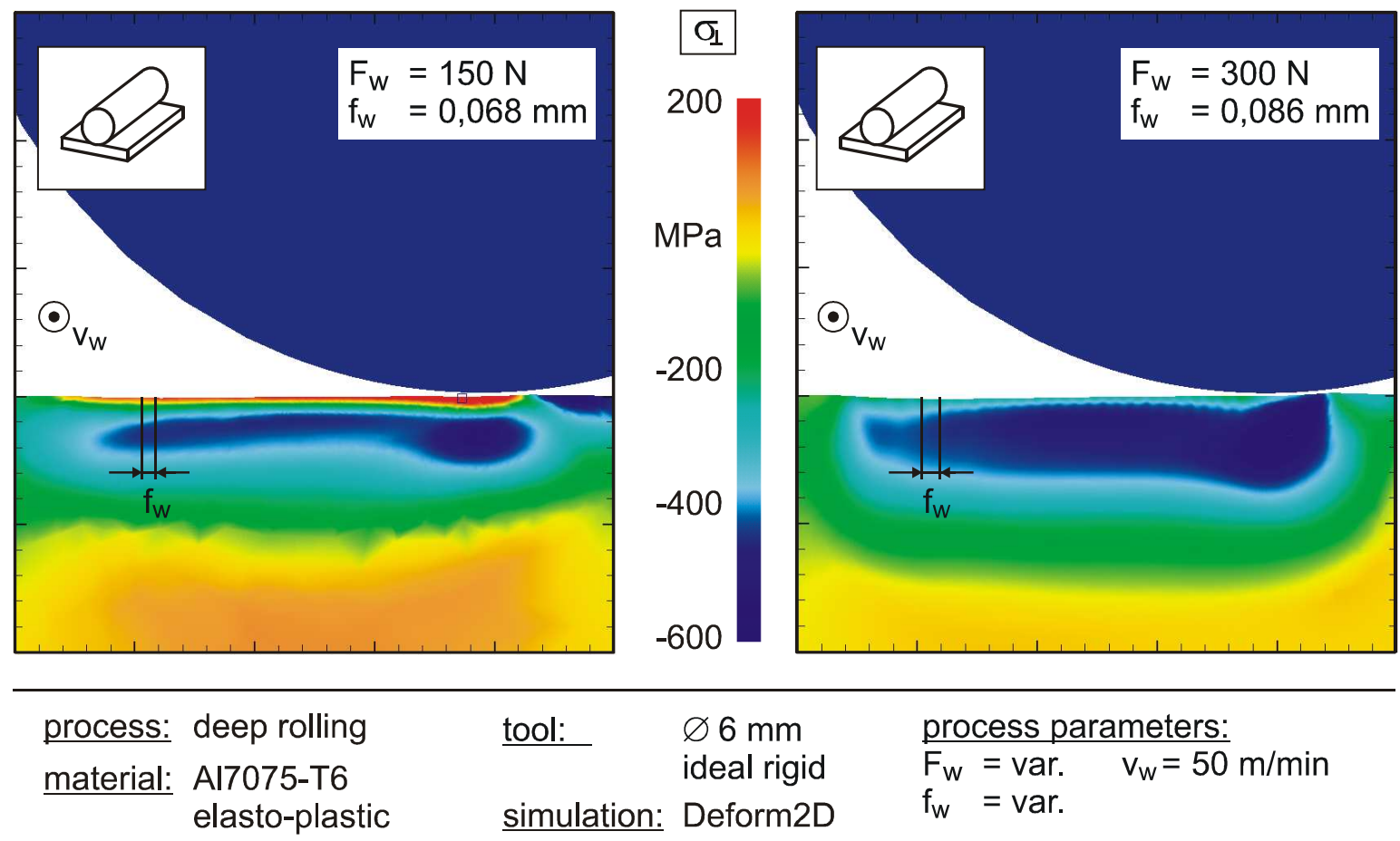

Dy/51650 @IFW

Fig. 11: Simulation of residual stresses due to the deep rolling process

Fig. 12 shows the simulated and experimentally determined residual stress distribution parallel and perpendicular to the rolling direction. A comparison shows a good qualitative correlation between the stress depth distributions. The maximum depth of the affected surface zone is overestimated by the simulation due to the simplifications used for the $2 \mathrm{D}$ model.

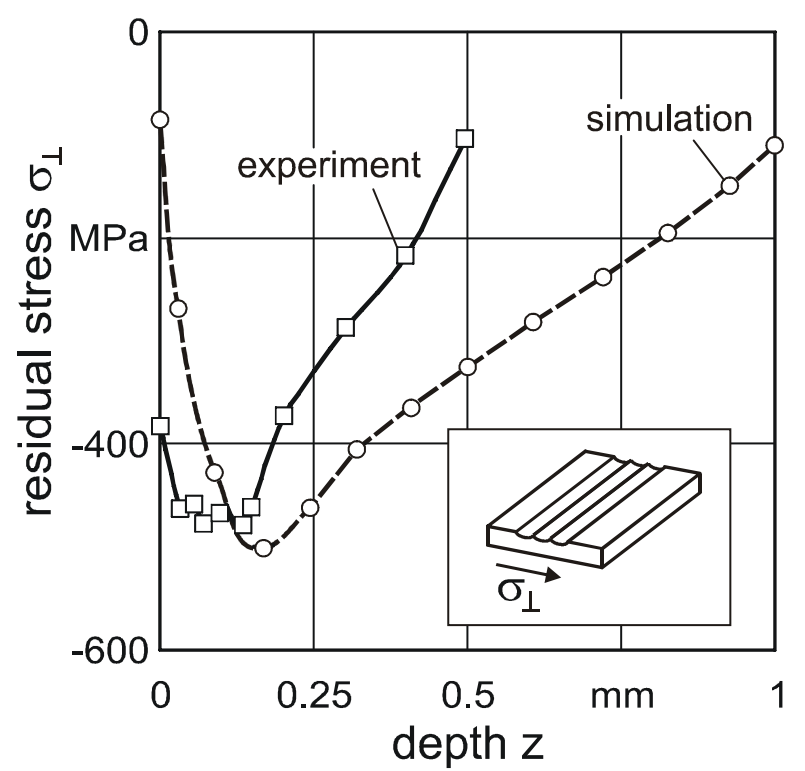

process: deep rolling material: Al7075-T6 elasto-plastic

tool: $\varnothing 6 \mathrm{~mm}$

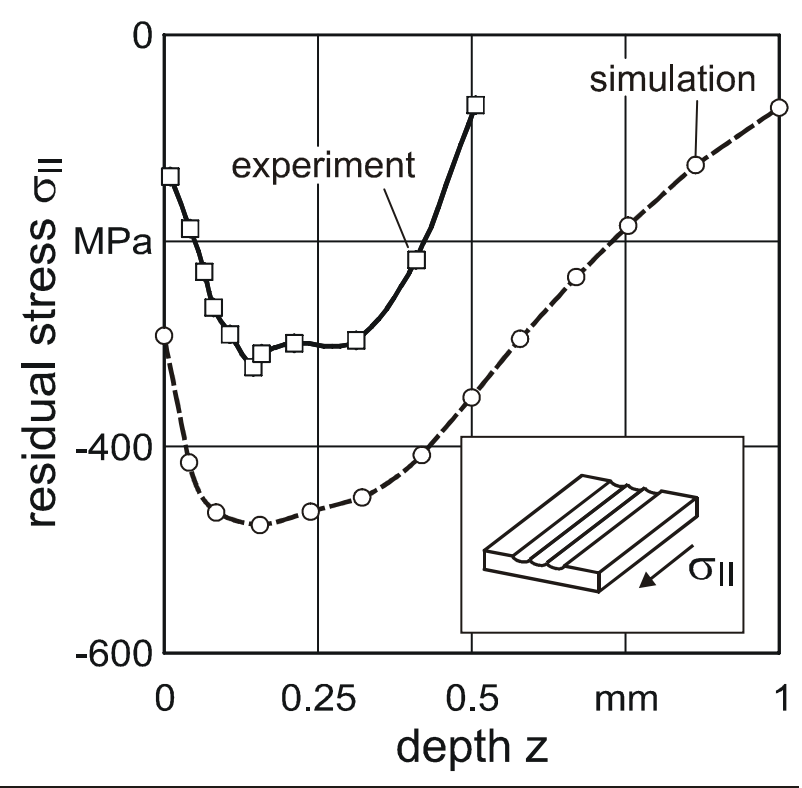
ideal rigid simulation: Deform2D process parameters:

$\mathrm{F}_{\mathrm{W}}=300 \mathrm{~N} \quad \mathrm{v}_{\mathrm{w}}=50 \mathrm{~m} / \mathrm{min}$ $f_{w}=0.086 \mathrm{~mm}$

Fig. 12: Simulation of depth resolved residual stress due to deep rolling 


\section{Results and their significance}

The main objective of the first period of the project is to examine the combination of the manufacturing processes „material separation“ and „modification of material properties“ into a single simultaneous process step. This is to be achieved by reducing the time delay between the processes and conducting the two processes of machining and surface modification within only one clamping and with one tool. Thus the fact that the surface is still heated and has not yet been chemically passivated after the material separation process can be used to adjust local material and component properties.

The machined surfaces are characterized by their roughness, their hardness, the surface residual stress state and the residual stress depth distribution. The decision on suitable process combinations is based on these workpiece properties. In the following, the essential results of the examinations of the separate processes and those of the combined process of turning and rolling are presented. For these latter examinations, a prototypic tool has been developed and used which allows a nearly simultaneous application of the processes turning and deep rolling.

\section{Turning}

The material separation process of turning has been investigated first, using the example of orthogonal turning. The influences of the tool geometry, the cutting speed and the feed on the subsurface zone properties have been investigated. Within the chosen parameter ranges, no systematic interdependency between the tool geometry (rake angle and clearance angle) and the subsurface zone properties has been observed (see Fig. 13).

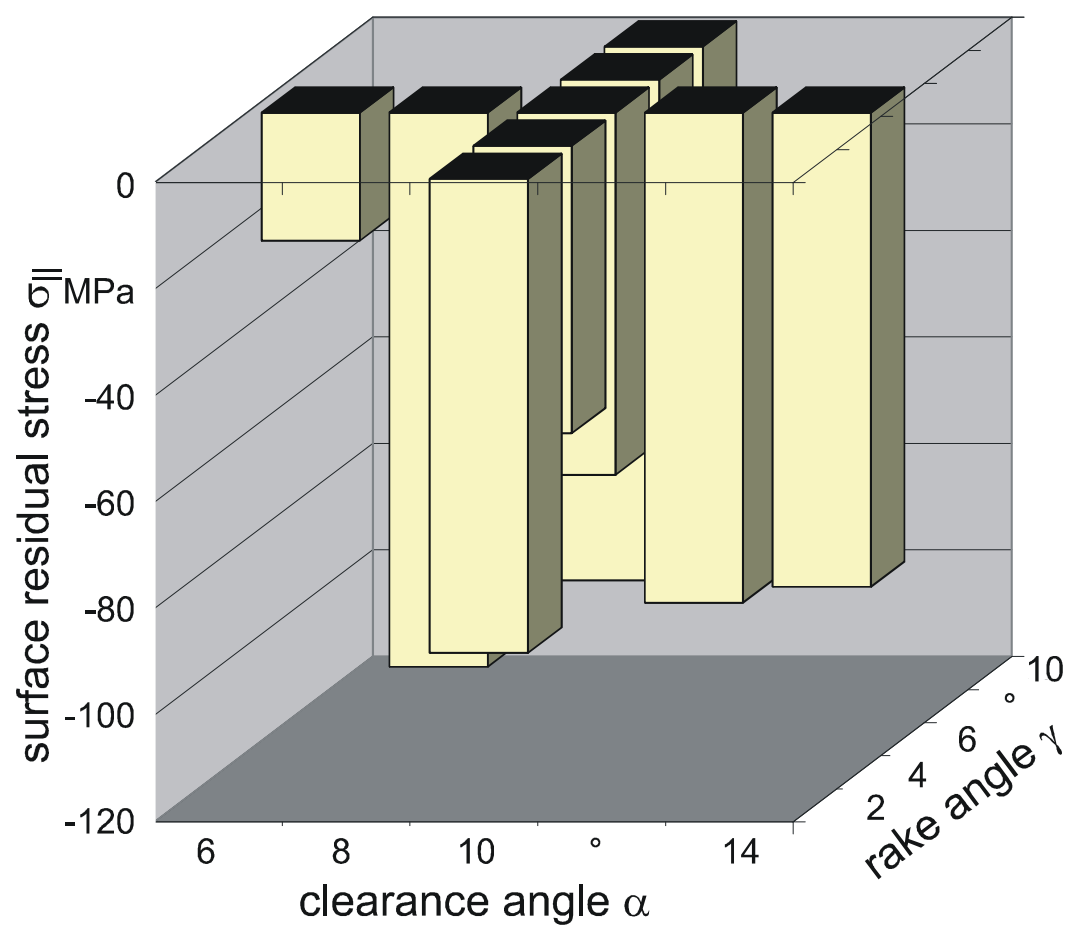

process:

orthogonal cutting

dry

material:

Al7075 T6

tool:

cemented carbide insert

$\mathrm{v}_{\mathrm{C}}=1250 \mathrm{~m} / \mathrm{min}$

$\mathrm{f}=0.20 \mathrm{~mm}$

Diffractometer:

Seifert XRD 3000 P

Bre/46445 @ IFW

Fig. 13: Surface residual stress in dependence of the tool geometry 
However, with regard to a variation in the process parameters, it has been observed that an increase in the feed leads to an increase in the roughness and in the penetration depth of the residual stresses (Fig. 14, right). The cutting speed only affects the residual stresses at the surface (Fig. 14, left).

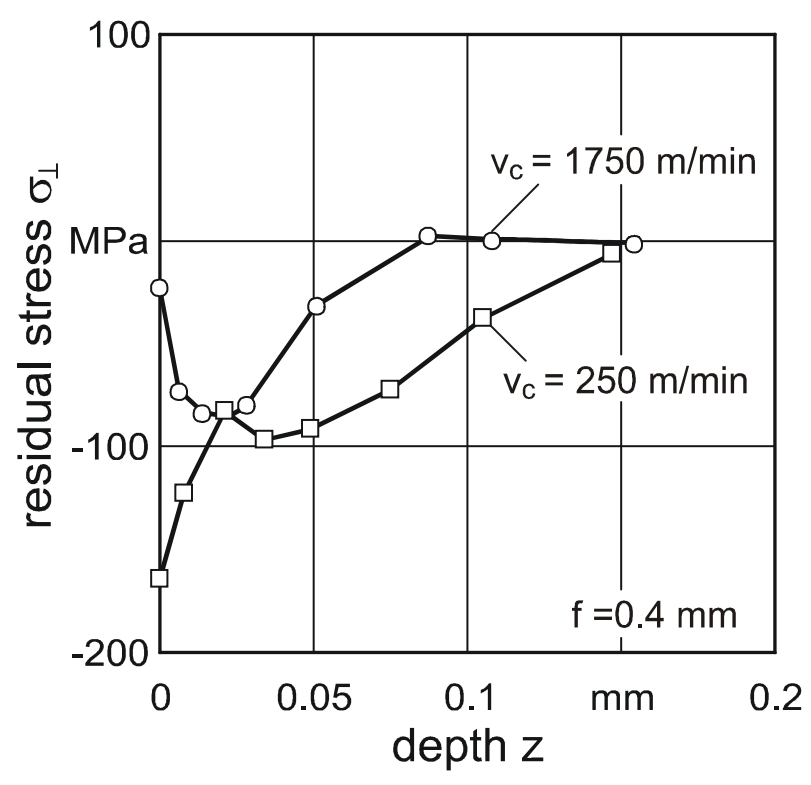

process: orthogonal turning material: Al7075-T6 tool: cutting insert $\alpha=10^{\circ}, \gamma=6^{\circ}$

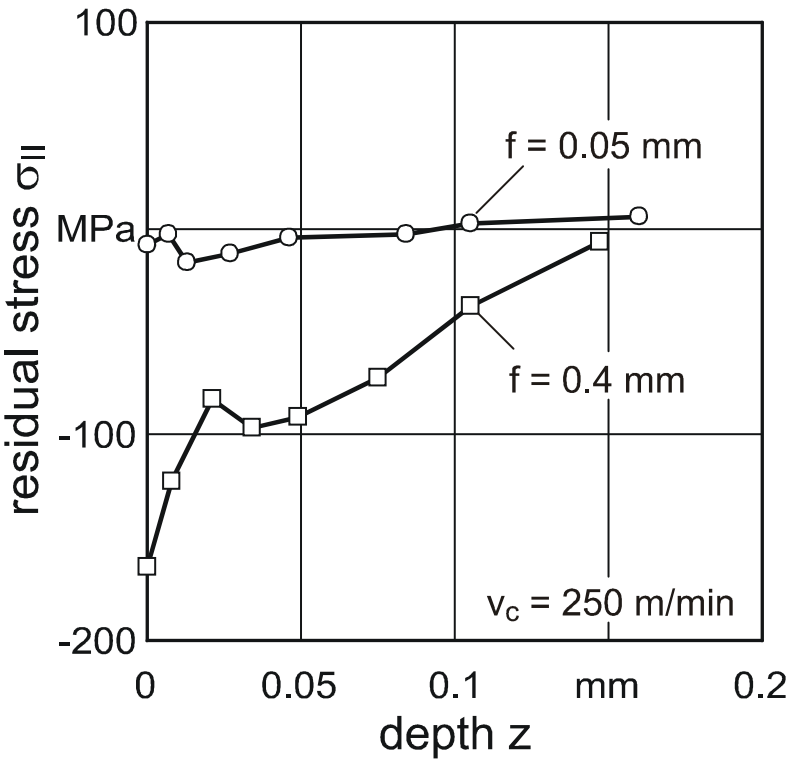

process parameters:

$a_{p}=4 \mathrm{~mm} \quad v_{c}=$ var.

$f=$ var.

Fig. 14: Influence of cutting speed and feed on the residual stress distribution

Dv/59298 @ IFW

The machining process causes a short temperature increase in the subsurface zone of the workpiece. However, direct thermographic or pyrometric temperature measurement on the freshly machined surface cannot provide significant results because of the low thermal emission coefficient and the resulting high reflectivity of aluminium.
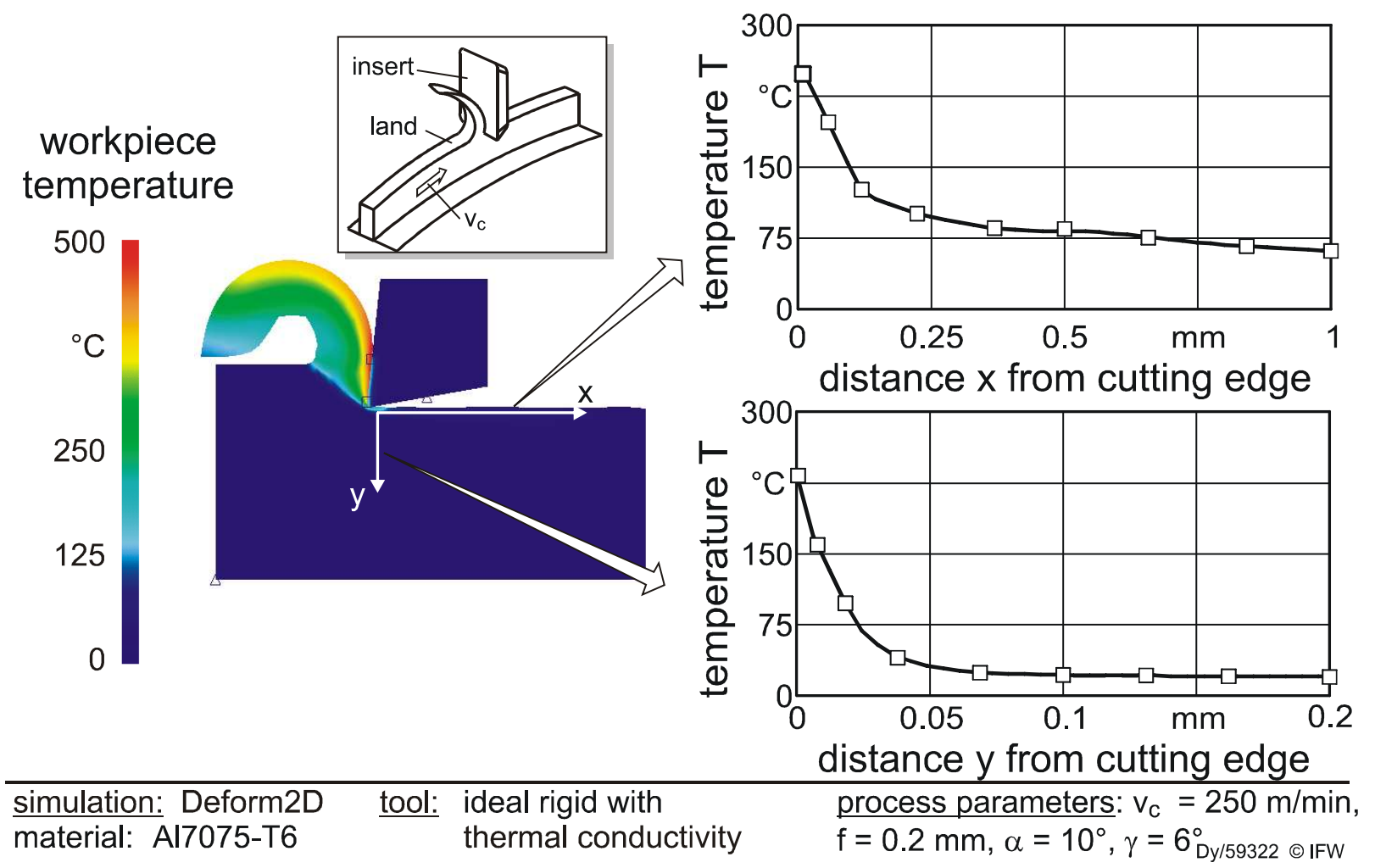

simulation: Deform2D material: Al7075-T6 tool: ideal rigid with thermal conductivity

Fig. 15: Calculated process temperatures in the orthogonal turning process 
The numeric simulations showed that the highest amount of heat is generated by friction on the rake face and is lead off by the chip (Fig. 15, left). The remaining heat in the subsurface zone after the process is especially interesting with regard to the subsequent hardening process. The simulation shows that the heat is quickly lead off into the inside of the workpiece due to the high thermal conductivity of the aluminium alloy. At a cutting speed of $\mathrm{v}_{\mathrm{c}}=250 \mathrm{~m} / \mathrm{min}$, the surface temperature after $\mathrm{t}=0.24 \mathrm{~ms}$ is below $\mathrm{T}=70^{\circ} \mathrm{C}$. At this cutting speed, this corresponds to a distance of $\mathrm{d}=1 \mathrm{~mm}$ from the cutting edge (Fig. 15, right). In order to use the increased temperature for the modification of the subsurface zone, the rubbing respectively rolling tool element has to be positioned as closely as possible to the cutting edge.

In summary the turning process, beneath its necessity to generate the surface contour, leads to low compressive residual stresses in the subsurface zone within a maximal depth of around $150 \mu \mathrm{m}$ under the workpiece surface. To modify the surface under an increased thermal load it is necessary to position the rubbing respectively rolling element as close as possible to the cutting edge.

\section{Rubbing}

The second focus in the first period of the project was on examining the material property change processes, which modify the subsurface zone properties without removing material. In rubbing processes, the forces at the contact areas between the two moving bodies, i. e. the workpiece and the rubbing tool, are used to introduce stresses into the working material. The relative speed between the workpiece and the tool also produces heat. In pure machining processes, this rubbing action is continuous throughout the tool flank face. Its effect changes with an increase in the flank face wear. In separate rubbing tests, conventional indexable inserts with an extremely negative tool orthogonal rake angle of $\gamma=-75^{\circ}$ are used. In the following, this angle is referred to as the rubbing angle $\gamma_{\mathrm{r}}$ (Fig. 16).

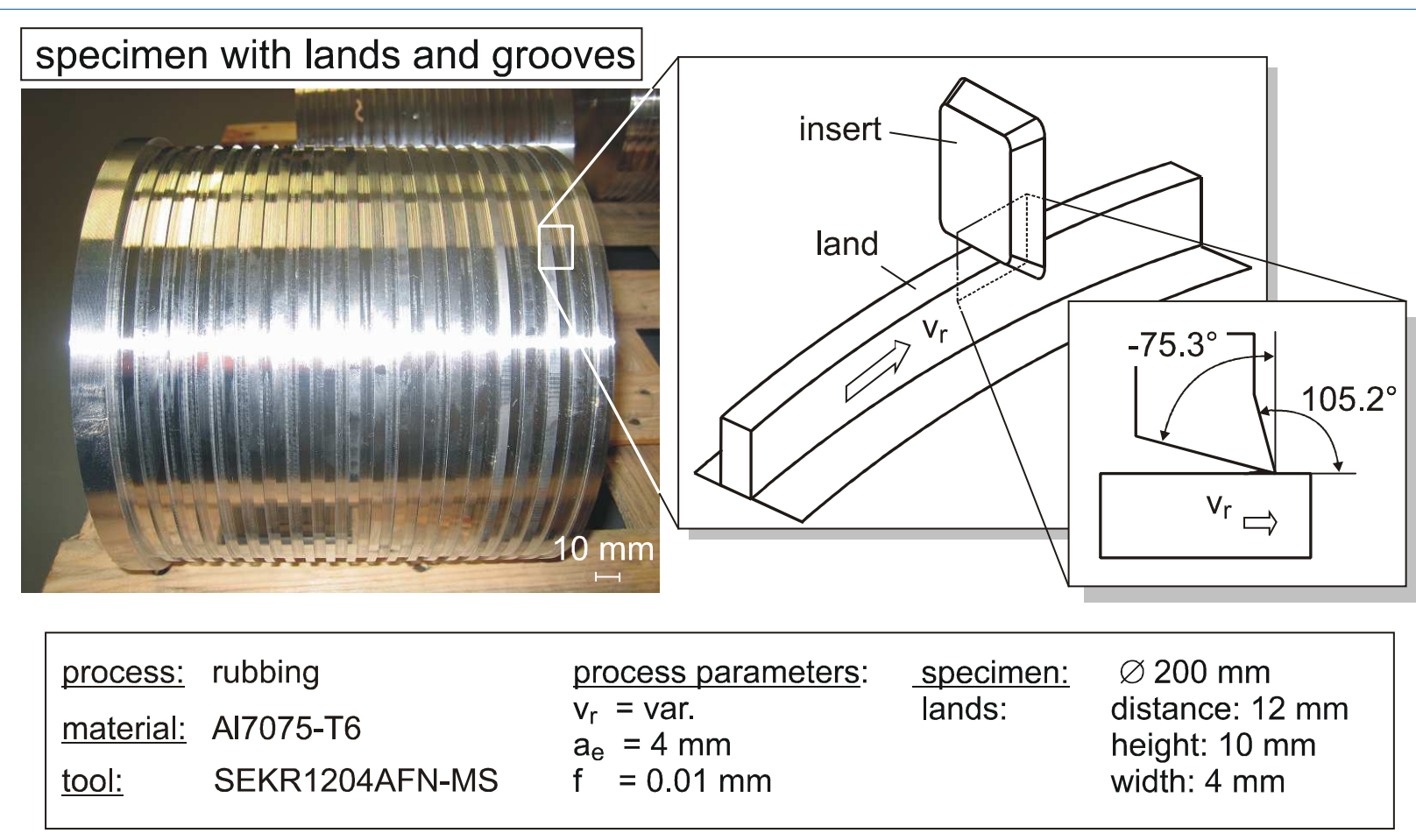

Dy/51624 @ IFW

Fig. 16: Scheme of the rubbing process

The rubbing tests have been conducted using the kinematics of an orthogonal turning process on a shaft with lands and grooves. We refer to this process as orthogonal rubbing. In the tests, the indexable insert penetrates the workpiece at a constant infeed, so that there is contact between the 
tool and the workpiece during ten revolutions of the workpiece. The simplified kinematics of this process allow for the description of the implied mechanisms and the comparison of the results with those of the process simulation.

Fig. 17 shows the impact of the rubbing velocity $\mathrm{v}_{\mathrm{r}}$ on the average surface roughness $\mathrm{Rz}$, the surface residual stress $\sigma$ and the hardness HB. With increasing rubbing speed the surface roughness and its standard deviation increase. All rubbing speeds over $\mathrm{v}_{\mathrm{r}}=5 \mathrm{~m} / \mathrm{min}$ cause intolerable high surface residual stresses. Furthermore, the rubbing process causes an increase in hardness of about $20 \mathrm{HB}$
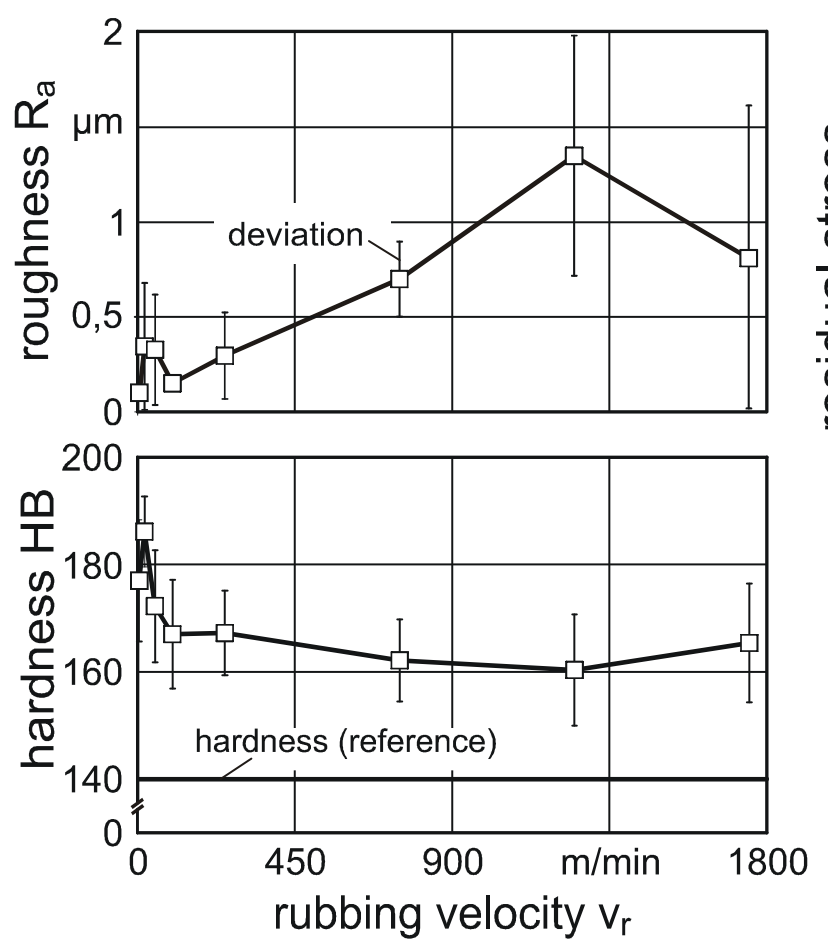

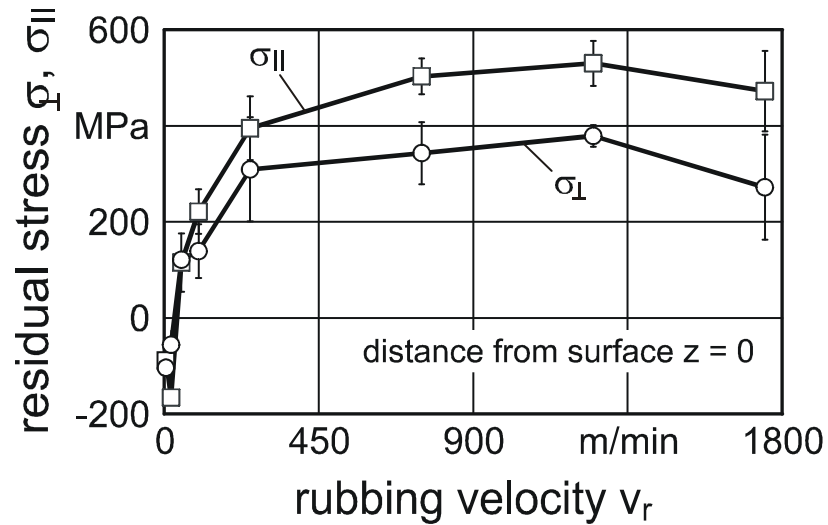

process: rubbing

process parameters:

$\mathrm{v}_{\mathrm{r}}=$ var.

$\mathrm{a}_{\mathrm{e}}=4 \mathrm{~mm}$

f $=0.01 \mathrm{~mm}$

material: Al7075-T6 tool:

cutting material: cemented carbide $\alpha=105.2^{\circ}$

$\gamma=-75.3^{\circ}$

Dy/51625 @ IFW

Fig. 17: Influence of the rubbing speed on roughness, hardness and surface residual stress

The influence of the rubbing speed on the residual stresses in the subsurface zone is shown in Fig. 18. A low rubbing speed leads to compressive residual stresses, while rubbing speeds of $\mathrm{v}_{\mathrm{r}}>50 \mathrm{~m} / \mathrm{min}$ result to increasing tensile residual stresses at the surface. This is caused by the thermal stress acting on the surface zone, which is itself due to friction between the workpiece and the tool.

The investigations show that the tool geometry plays an essential role in the rubbing process. Due to the negative rubbing angle and the chosen feed value, the workpiece material is not separated by the tools cutting edge, but is squeezed out. Furthermore, the examinations show that the material flows to the sides of the lands as a result of this plastic deformation. Thus, the lands are broadened; additional material is piled up in front of the tool edge. There are abrupt disruptions of piled-up material, and some material is rubbed into the workpiece surface by the tool. 


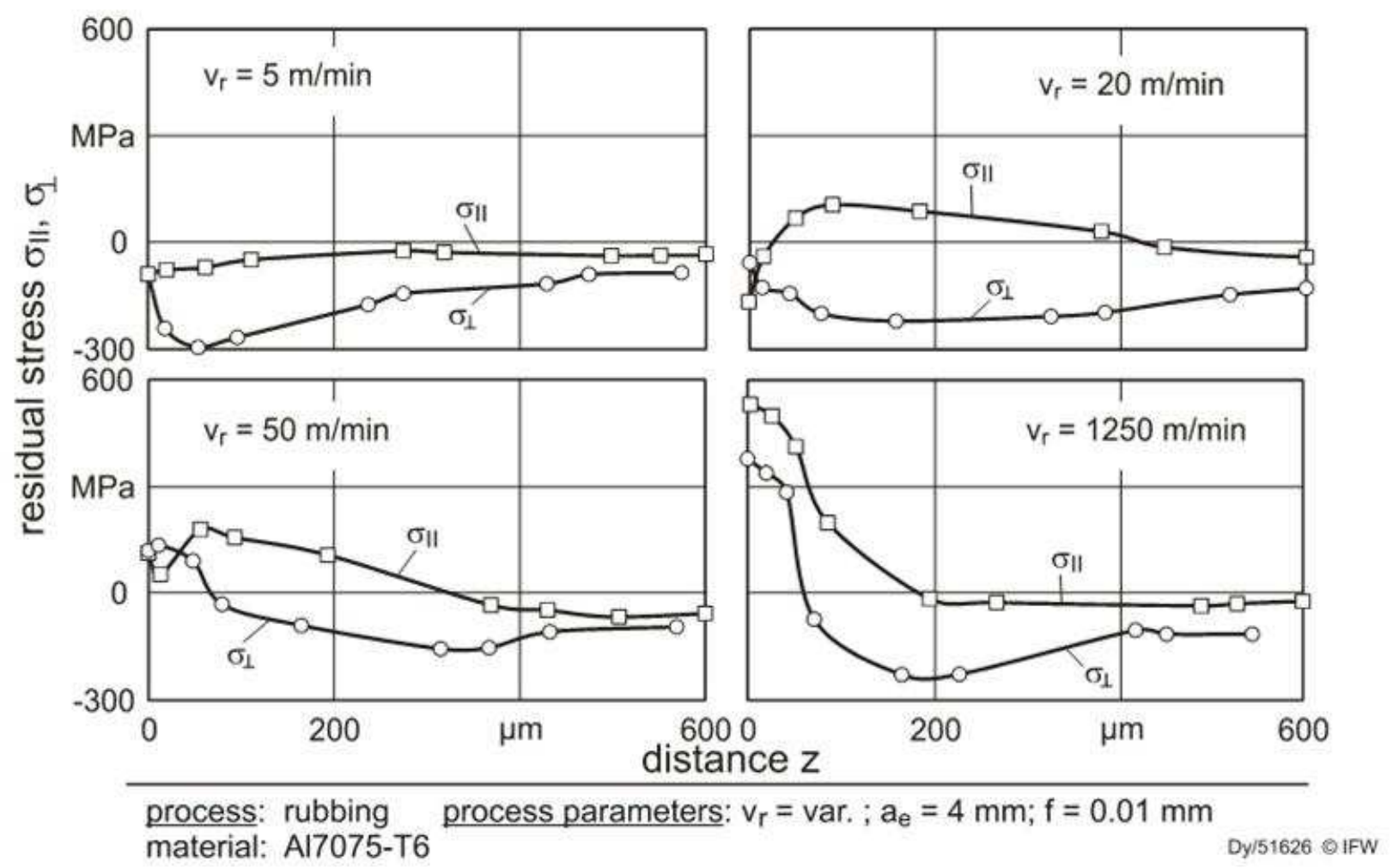

Fig. 18: Influence of the rubbing speed on the residual stress distribution in orthogonal rubbing

For the FEM simulation, an infinite land width and a shaft with an infinite diameter is assumed, which means only the compression of the material in front of the tool is simulated. Fig. 19 (left) shows the stresses occurring in the rubbing process. The simulations show that the process forces are rising continuously with a constant feed (Fig. 19, right).
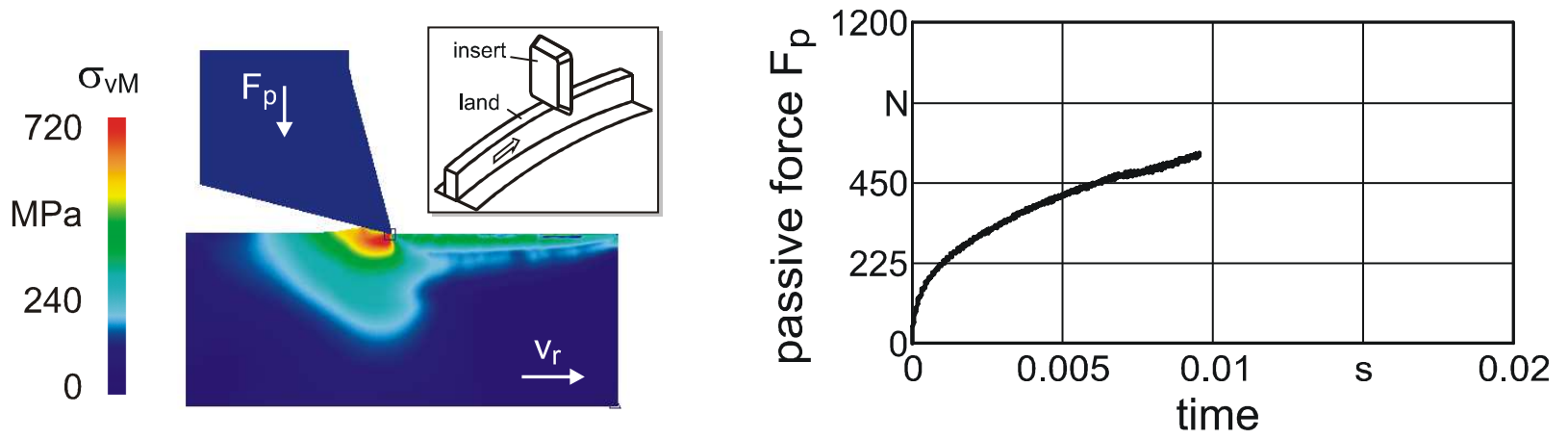

$$
\begin{aligned}
& \text { simulation: Deform2D tool: } \\
& \text { material: Al7075-T6 ideal rigid } \\
& \text { process parameters: } v_{r}=20 \mathrm{~m} / \mathrm{min}, f_{r}=0.01 \mathrm{~mm}, \gamma_{r}=-75^{\circ}
\end{aligned}
$$

Fig. 19: Simulated passive force in the rubbing process

Additionally, the influence of a defined surface pressure on the subsurface zone properties by means of a force controlled rubbing process is currently investigated. The experimental setup is presented in Fig. 20. The surface pressure is adjusted by varying the spring preload and the contact length between the tool and the workpiece. The contact length is varied by means of tailored ground cutting edges. 


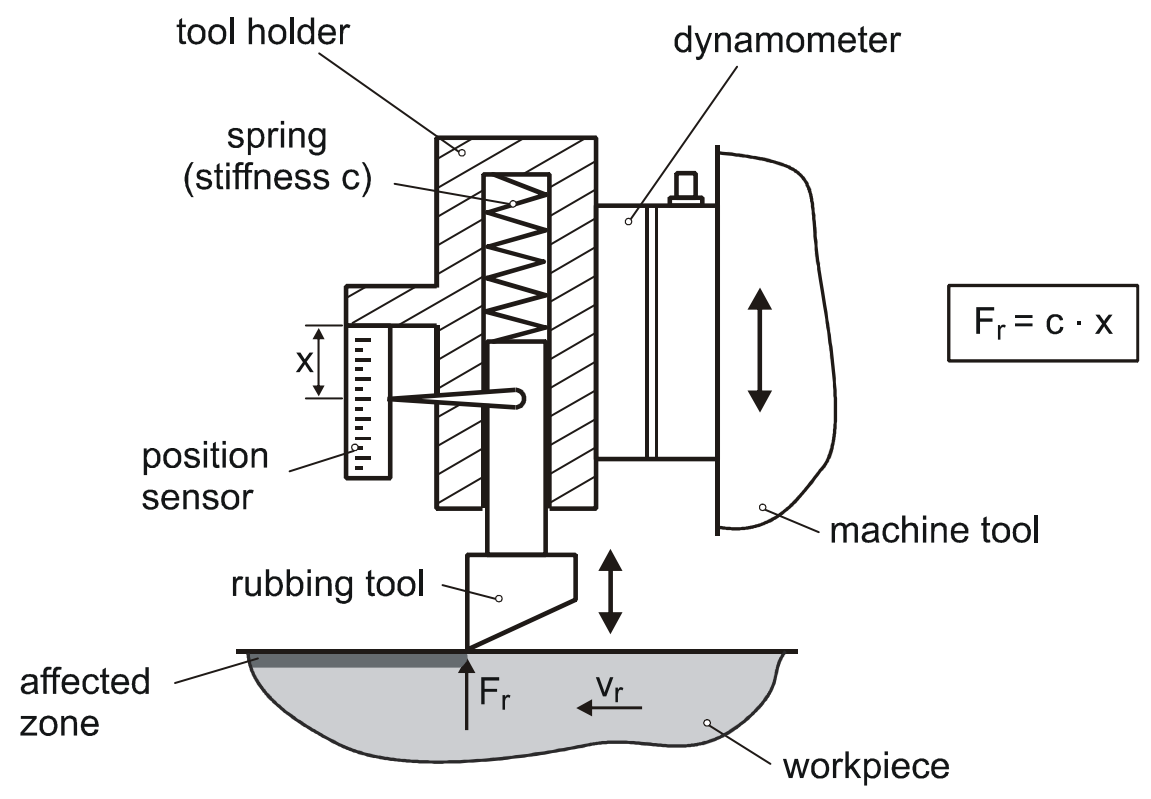

Dy/59334 ㄷ IFW

Fig. 20: Force controlled rubbing

In summary the rubbing process leads to a significant decrease in surface quality in comparison to the turning process. For rubbing speeds, obtaining the range of cutting velocities for aluminium alloys to realize a combination of both processes, strong tensile residual stresses occur, which will reduce the durability of machined components.

\section{Deep rolling}

A further process to modify the subsurface zone properties which has been investigated is that of deep rolling. The influence of the rolling force, the distance between the rolling paths, the diameter of the rolling ball and the rolling speed on the surface properties and the subsurface zone properties is examined. Fig. 21 shows the experimental set-up of the deep rolling process. 


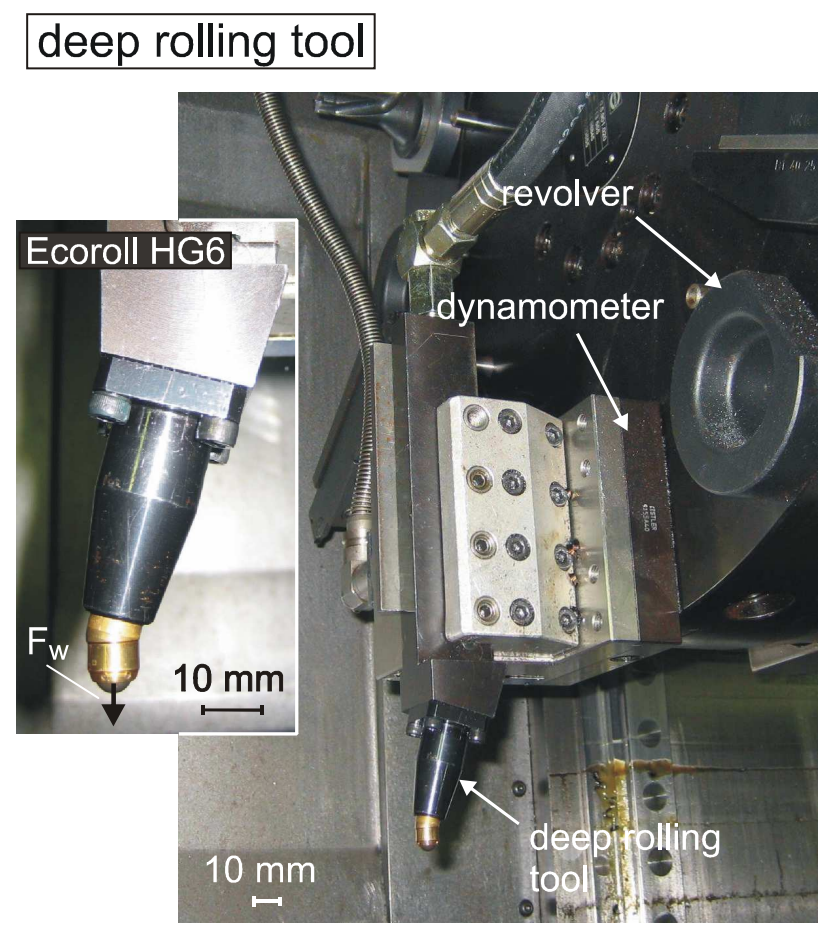

tool: $\quad$ Ecoroll HG6

material: $\quad$ Al7075-T6

process parameter:

rolling force $\quad F_{w}=50$ bis $600 \mathrm{~N}$

rolling feed $\quad f_{w}=0.043$ bis $0.214 \mathrm{~mm}$

rolling speed $\quad v_{w}=50 \mathrm{~m} / \mathrm{min}$
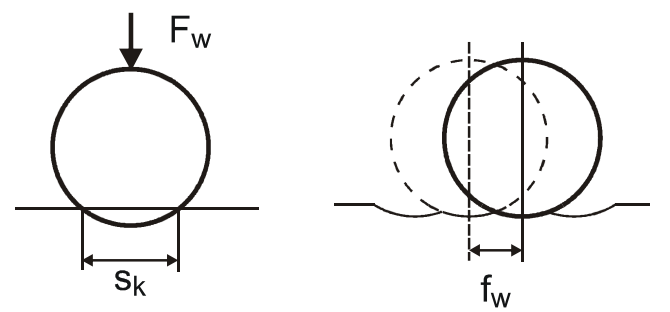

Fig. 21: Set-up of the deep rolling process

An increase in the rolling force leads to an increased penetration depth of the compressive residual stresses (Fig. 22).
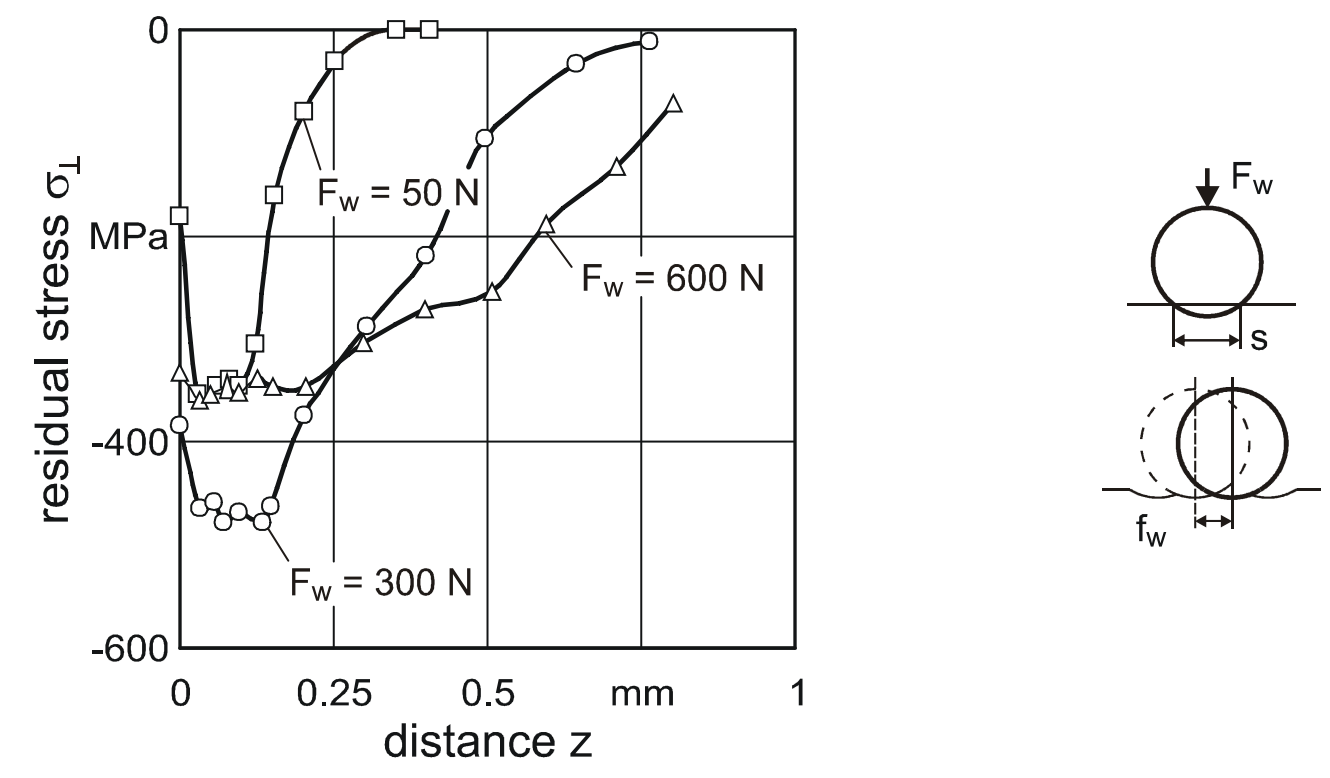

process: deep rolling

tool: Ecoroll HG6

$$
\begin{aligned}
& \text { process parameters: } \\
& \mathrm{V}_{\mathrm{w}}=50 \mathrm{~m} / \mathrm{min} \\
& \mathrm{f}_{\mathrm{w}}=0.043 \mathrm{~mm} \quad \mathrm{~F}_{\mathrm{w}}=\text { var. }
\end{aligned}
$$

Dy/59325 @ IFW

Fig. 22: Influence of the parameter setting on the residual stresses in deep rolling

An increase in the feed leads to increased surface roughness with only a slight change in hardness (Fig. 23). A change in the rolling ball diameter from $d_{w}=6 \mathrm{~mm}$ to $d_{k}=13 \mathrm{~mm}$ has no significant influence on the residual stresses. 


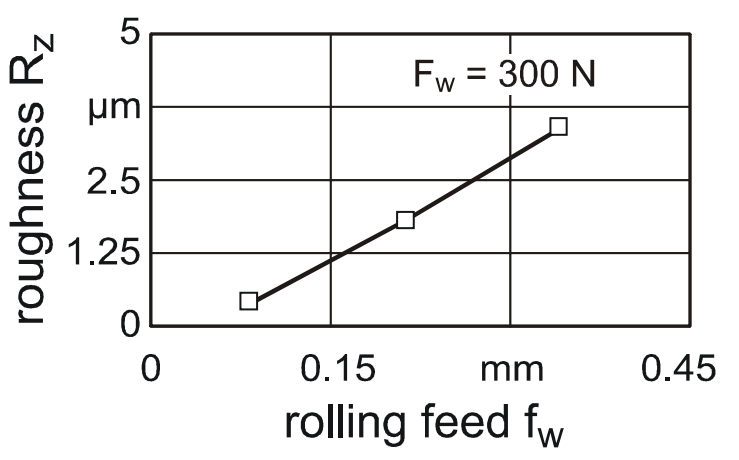

process: deep rolling material: Al7075-T6

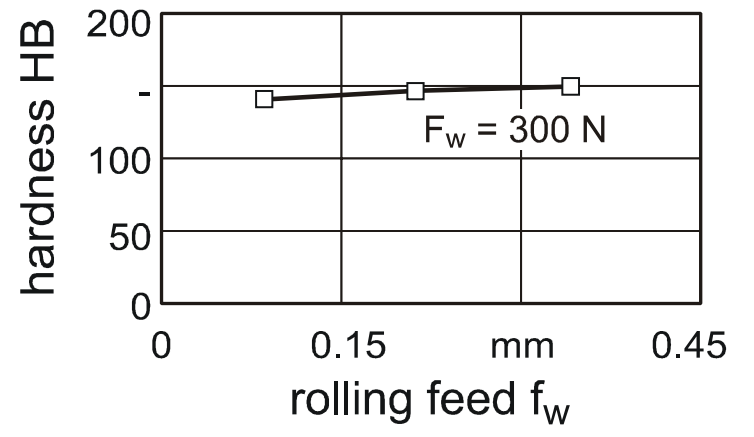

process parameters:

$v_{\mathrm{w}}=50 \mathrm{~m} / \mathrm{min} \mathrm{f}_{\mathrm{w}}=$ var.

$\mathrm{F}_{\mathrm{w}}=300 \mathrm{~N}$

Dy/59325 @IFW

Fig. 23: Influence of the parameter setting on the surface properties in deep rolling

The relevant cutting speeds for turning aluminium alloys are within the range of $\mathrm{v}_{\mathrm{c}}=500$ $2000 \mathrm{~m} / \mathrm{min}$. In the deep rolling process, the recommended rolling speeds are considerably lower $\left(\mathrm{v}_{\mathrm{w}}=50-200 \mathrm{~m} / \mathrm{min}\right)$. In order to combine the two processes, the conventional rolling speeds have to be exceeded significantly. The deep rolling tests have been conducted with rolling speeds of $\mathrm{V}_{\mathrm{w}}=50-1150 \mathrm{~m} / \mathrm{min}$. The results show that it is generally possible to apply significantly increased speeds compared to conventional rolling processes (Fig. 24).

However, at specific rolling speeds (e.g. $\mathrm{v}_{\mathrm{w}}=300 \mathrm{~m} / \mathrm{min}, \mathrm{v}_{\mathrm{w}}=1100 \mathrm{~m} / \mathrm{min}$ ), depending on the rolling force, chatter vibrations occur. The effects of the chattering are visible on the workpiece surface and can be quantified by a significantly increased roughness depth $\mathrm{R}_{\mathrm{z}}$. The surface hardness and surface residual stress are not affected by chatter occurrence.
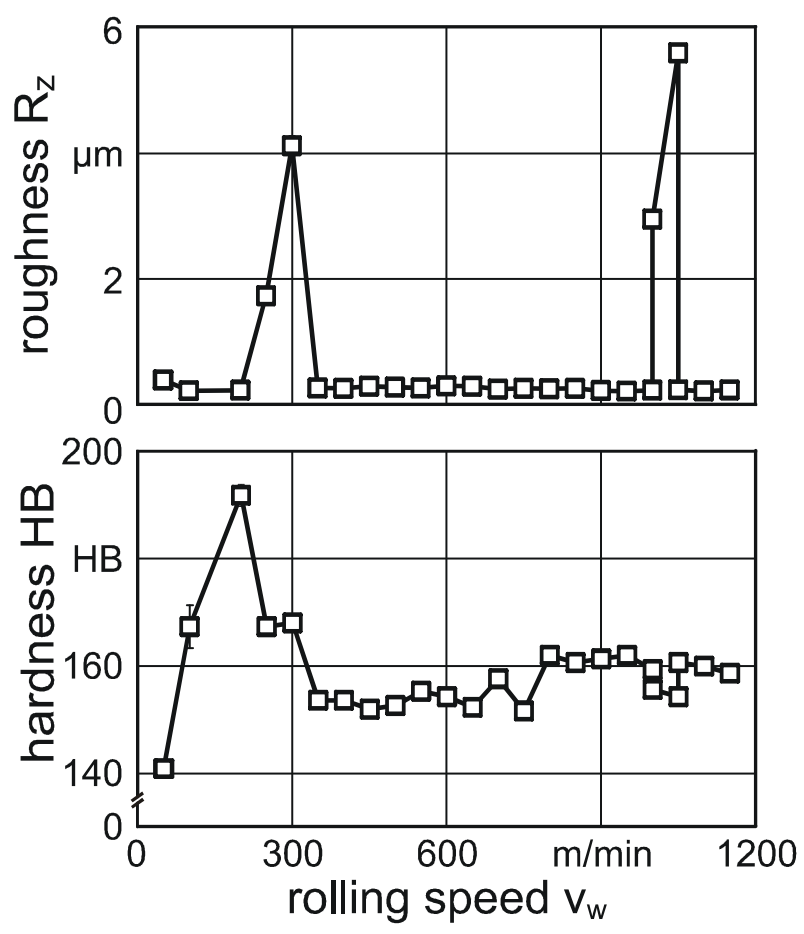

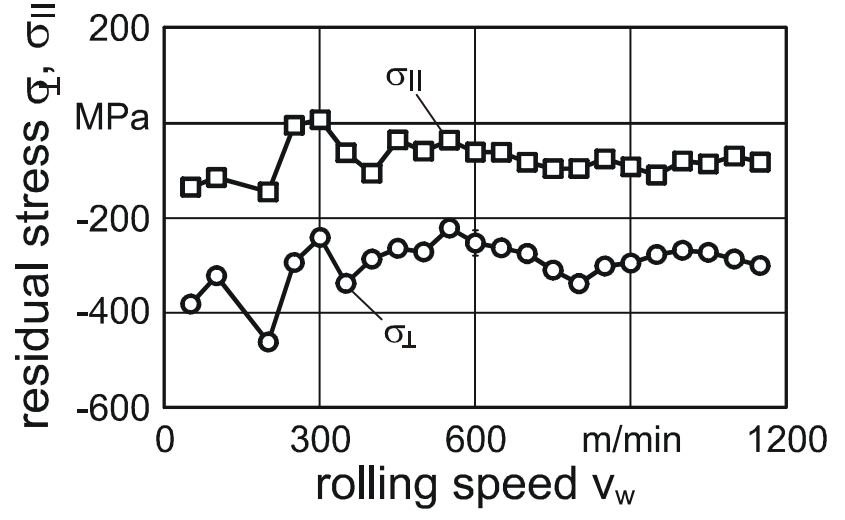

process: deep rolling material: Al7075-T6 tool: $\quad$ Ecoroll HG6

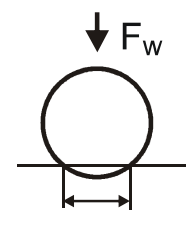

process parameters: $\quad \mathrm{s}$

$\mathrm{F}_{\mathrm{w}}=300 \mathrm{~N}$

$f_{\mathrm{w}}=0.086 \mathrm{~mm}$

$\mathrm{v}_{\mathrm{w}}=$ variiert

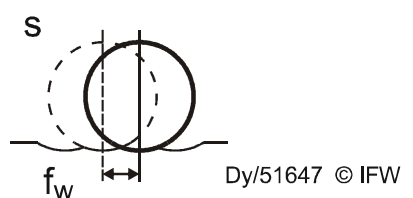

Fig. 24: Deep rolling at high rolling speeds 
FEM simulations are conducted in order to gain further knowledge on these effects. Therefore, the width of a single rolling path from the experiments is compared with one of the simulations to determine the equivalent force for the model. The simulation shows that the feed $f_{w}$ has no significant influence on the residual stresses within the chosen range of parameters. This is due to the fact that the feed is considerably smaller than the contact length between the rolling ball and the workpiece (for $F_{r}=300 \mathrm{~N}$, the contact length in the feed direction is about $1=1 \mathrm{~mm}$ (Fig. 25). Thus the penetration depth of the residual stresses does not depend on the feed.
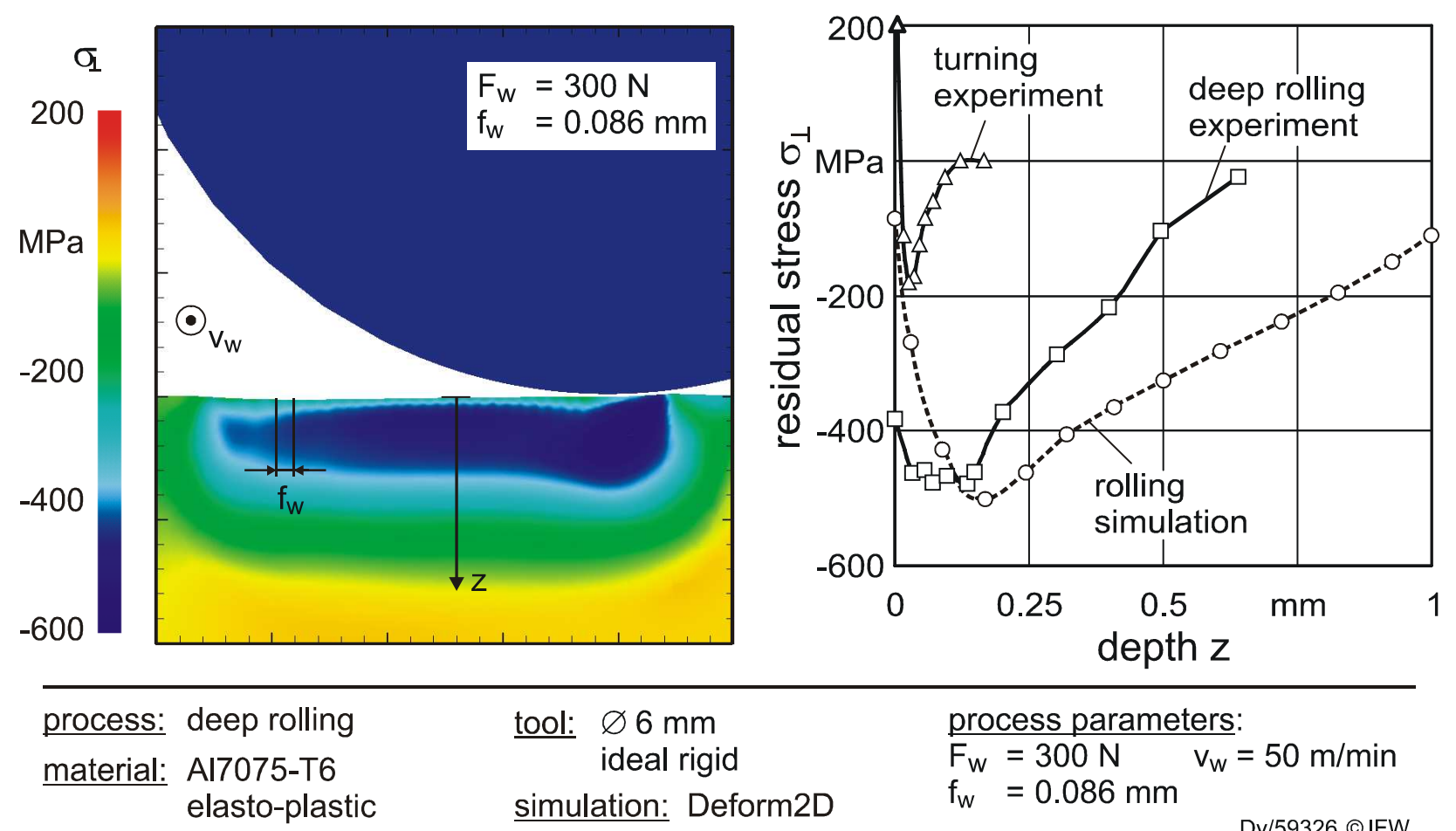

$$
\begin{aligned}
& \text { process parameters: } \\
& \mathrm{F}_{\mathrm{w}}=300 \mathrm{~N} \quad \mathrm{~V}_{\mathrm{w}}=50 \mathrm{~m} / \mathrm{min} \\
& f_{\mathrm{w}}=0.086 \mathrm{~mm}
\end{aligned}
$$

Fig. 25: Residual stresses after the deep rolling process

In summary the deep rolling process is able to increase the surface quality and compressive residual stresses in the subsurface layer. Furthermore it can be used at rolling speeds which are comparable to cutting speeds for aluminium alloys. Accordingly, it is predestined for the application in a combined process.

\section{Sequential turning and rubbing:}

The first step to analyze combined processes is the investigation of sequential processes. Hence it is examined if the preceding turning process has an influence on the resulting subsurface zone properties after the rubbing process. Therefore, the rubbing process is implemented by external cylindrical rubbing using cylindrical specimens. The specimens are turned with different setting parameters and are rubbed with constant setting parameters after they have cooled down to ambient temperature. The subsequent analysis of the subsurface zone shows that the parameter setting of the sequential turning process only has a slight influence on the subsurface zone properties after the rubbing process (Fig. 26).

Both the compressive and the tensile residual stresses can be introduced up to a penetration depth of $\mathrm{z}=1 \mathrm{~mm}$ into the subsurface zone depending on the parameter setting in the turning and the rubbing process. However, the surface roughness is very high compared to the separate turning process because of the piled-up material in front of the rubbing tool edge, and the roughness values scatter over a wide range because of the reduced vibration resistance of the process. Compressive residual stresses are only produced at low rubbing speeds. 


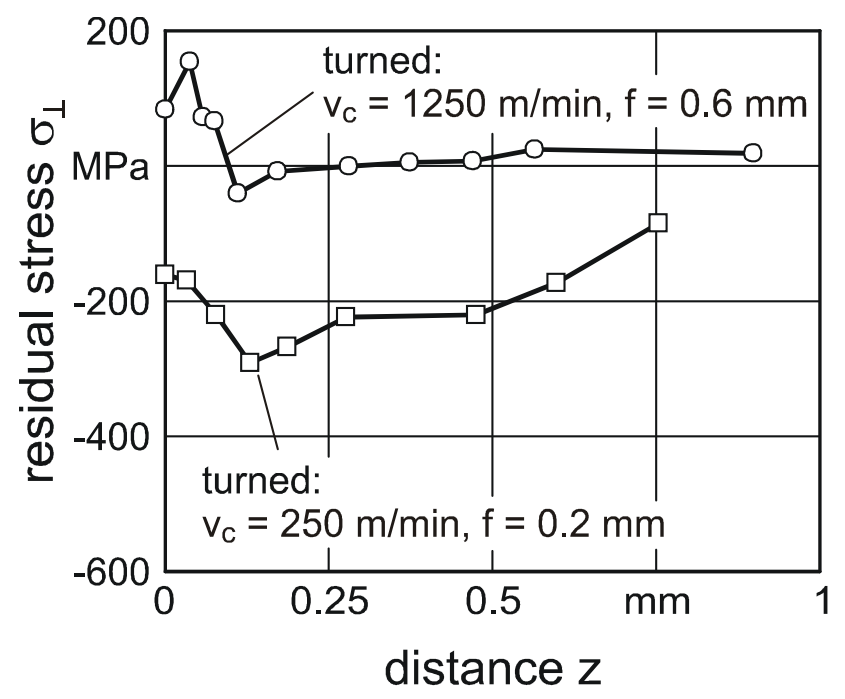

process: rubbing material: Al7075-T6

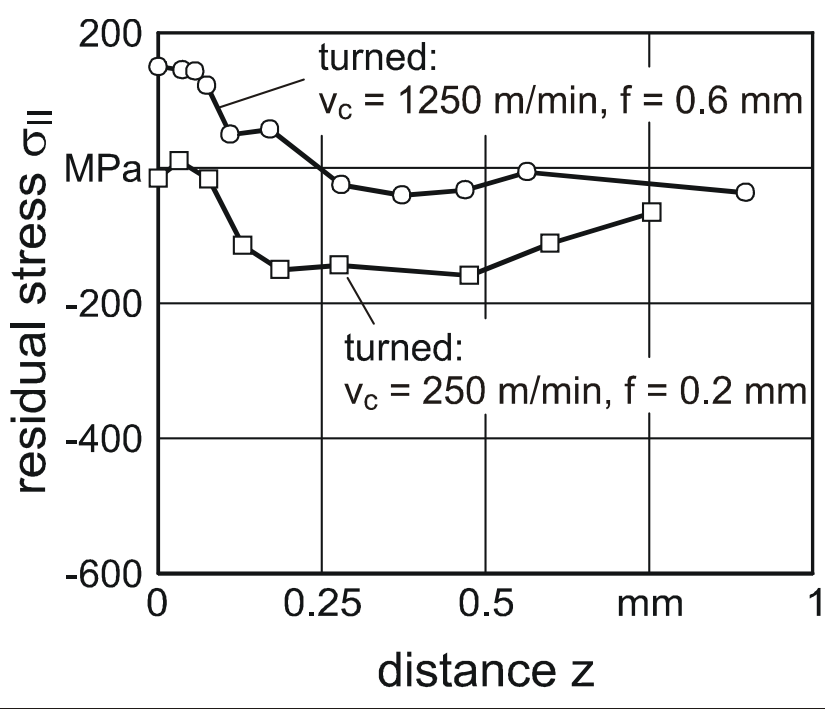

process parameters:

turning $1-v_{\mathrm{C}}=250 \mathrm{~m} / \mathrm{min}, \mathrm{f}=0.2 \mathrm{~mm}$ turning $2-v_{c}=1250 \mathrm{~m} / \mathrm{min}, \mathrm{f}=0.6 \mathrm{~mm}$ rubbing $-v_{r}=20 \mathrm{~m} / \mathrm{min}, f_{\mathrm{W}}=0.25 \mathrm{~mm}$, $\mathrm{F}_{\mathrm{rMax}}=600 \mathrm{~N}$ Dv/59332 @ IFW

Fig. 26: Influence of the turning process on the residual stress distribution after the rubbing process

Fig. 27 shows the simulation of the combined processes turning and rubbing. The tool consists of a cutting and a rubbing part and is build out of $n=1883$ elements, whereas the workpiece needs $n=3000-9000$ elements. The results are verified using the experimental data, thus providing basic knowledge on the physical processes occurring in the processes.
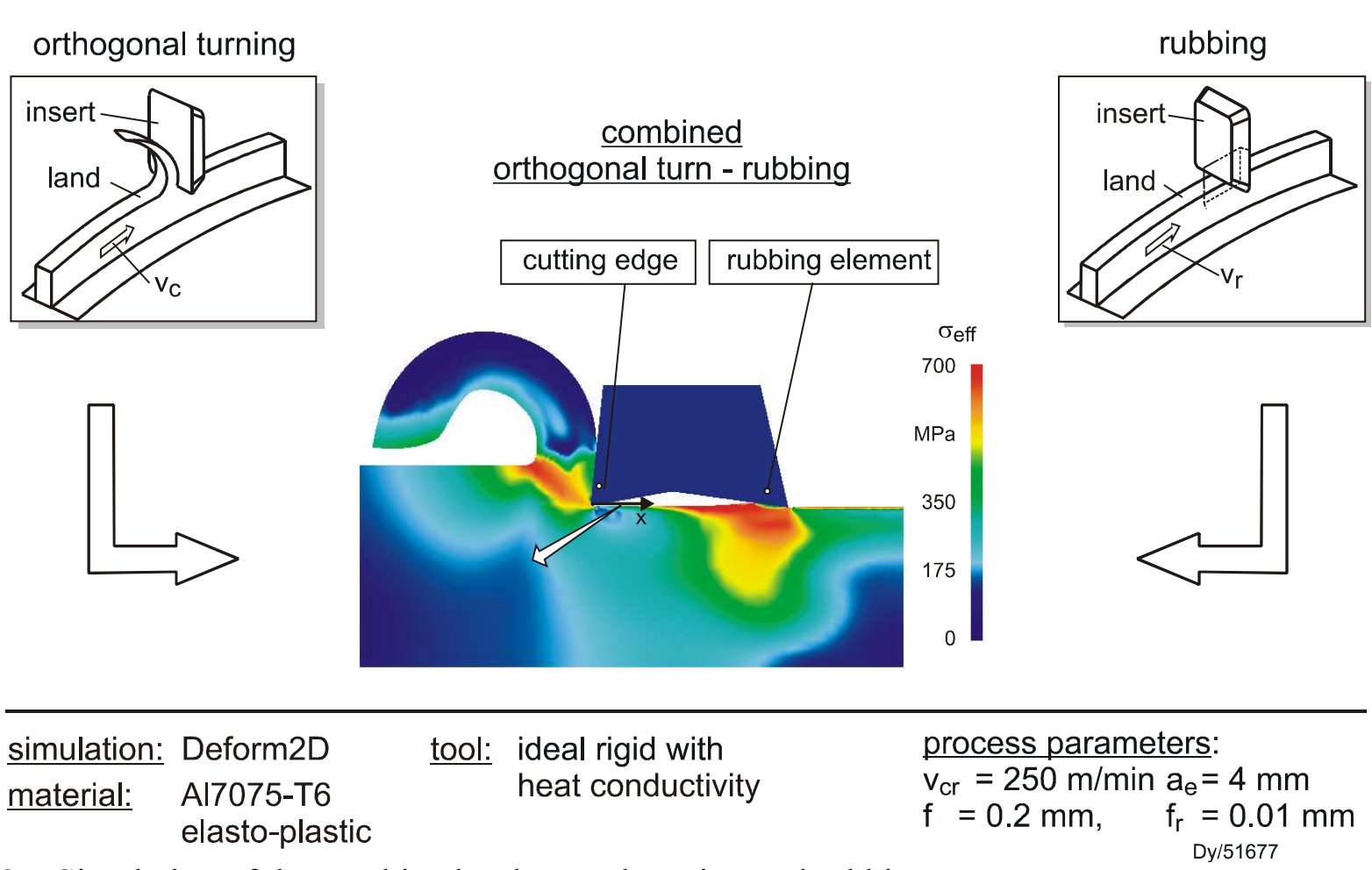

Fig. 27: Simulation of the combined orthogonal turning and rubbing process

In summary, the instability of the process and the limited process parameter ranges available for the introduction of compressive residual stresses limit considerably the possibilities for a successful combination of the turning and rubbing processes. 


\section{Sequential turning and deep rolling:}

In the sequential turning and deep rolling process, the rolling speed is an important influencing factor. The relevant cutting speeds for turning aluminium alloys are within the range of $\mathrm{v}_{\mathrm{c}}=500$ $2000 \mathrm{~m} / \mathrm{min}$. In the deep rolling process, the recommended rolling speeds are considerably lower $\left(\mathrm{v}_{\mathrm{w}}=50-200 \mathrm{~m} / \mathrm{min}\right)$. In order to combine the two processes, the conventional rolling speeds have to be exceeded significantly. The deep rolling tests have been conducted with rolling speeds of $\mathrm{V}_{\mathrm{w}}=50-1150 \mathrm{~m} / \mathrm{min}$. The results show that it is generally possible to apply significantly increased speeds compared to conventional rolling processes. However, at specific rolling speeds, depending on the rolling force, chatter vibrations occur. The effects of the chattering are visible on the workpiece surface and can be quantified by a significantly increased roughness depth $\mathrm{R}_{\mathrm{z}}$.

The simulation of the sequential turning and deep rolling considers the residual stress state after turning for the simulation of the deep rolling process. Fig. 28 shows the residual stress depth distribution for the sequent processes turning and deep rolling. The comparison with Fig. 12 shows no effect of the preceding turning process on the residual stress state after deep rolling, because the Hertzian stress induced by the rolling process significantly exceeds that of the turning process.
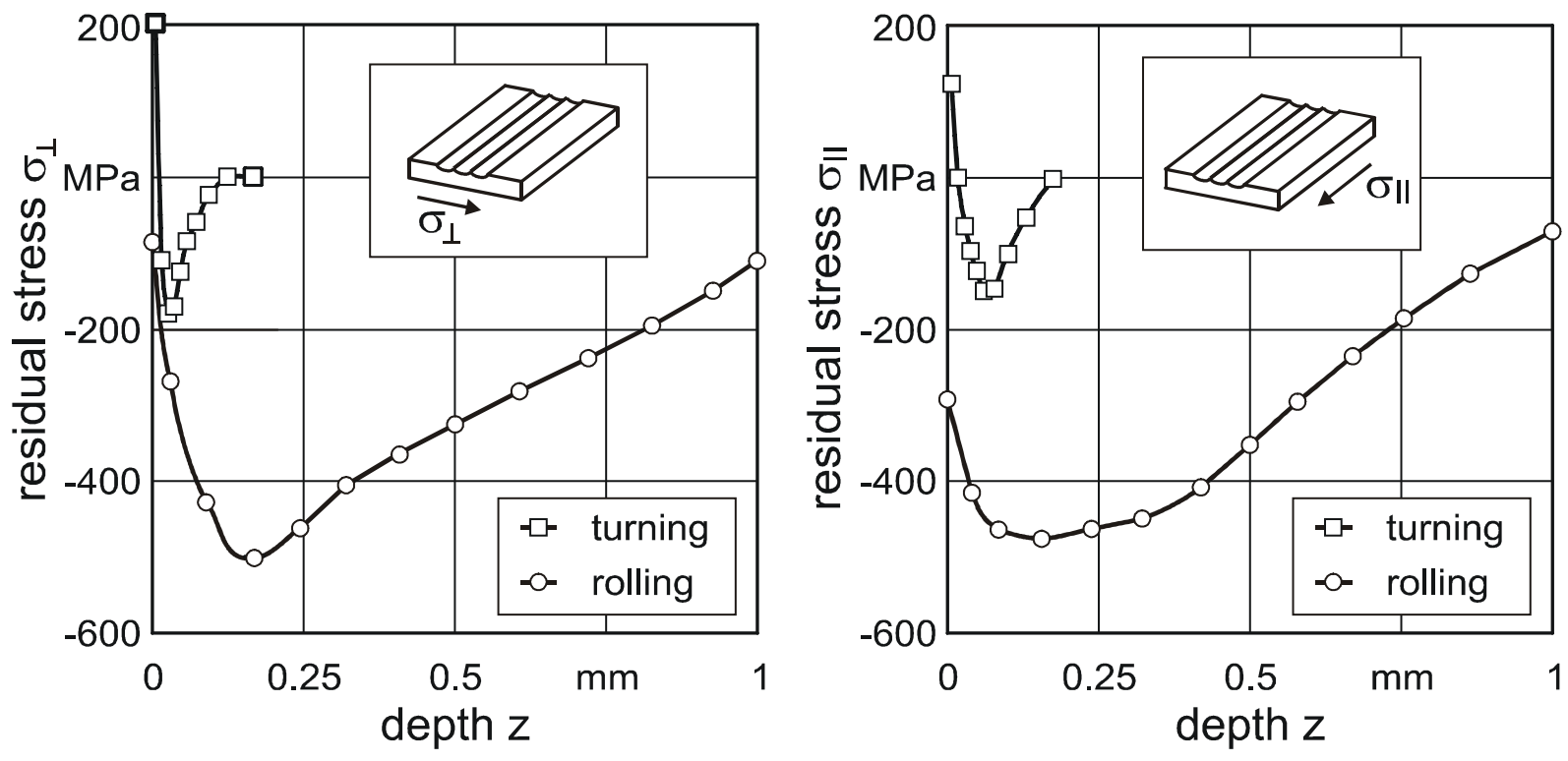

\begin{tabular}{|c|c|c|}
\hline rocess: $\mathrm{d}$ & tool: $\varnothing 6$ & process parameters: \\
\hline $\begin{aligned} & \text { al: } \text { Al70 } \\
& \text { elas }\end{aligned}$ & $\begin{array}{l}\text { ideal rigid } \\
\text { simulation: Deform2D }\end{array}$ & $\begin{array}{l}\mathrm{F}_{\mathrm{w}}=300 \mathrm{~N} \quad \mathrm{v}_{\mathrm{w}}= \\
\mathrm{f}_{\mathrm{w}}=0.086 \mathrm{~mm}\end{array}$ \\
\hline
\end{tabular}

Dy/51727 @ IFW

Fig. 28: Residual stress depth distributions after sequential turning and deep rolling

Apparently, the preceding turning process has no influence on the subsurface zone properties after the deep rolling process. This is due to the fact that the deep rolling process affects considerably higher depths of the subsurface zone than the cutting process. In summary the combination of turning and deep rolling is suitable for the development of a combined rolling-turning tool.

\section{Combined turning and rolling with prototypic turn-rolling tool}

The results of the deep rolling examinations show that a large range of process parameters is available to attain the desired subsurface zone modifications in a stable process. Compressive residual stresses with penetration depths of $z>500 \mu \mathrm{m}$ can be induced along with a high surface quality. Therefore, the process of combined turning and rolling is implemented using a new developed prototypic combined tool. 
The process is conducted in the peripheral direction using rotation-symmetric specimens. In order to minimize the time delay between the machining and the surface layer modification process, the indexable insert is followed by the rolling ball as closely as possible. Furthermore, the rolling ball is installed in the newly generated path of the cutting tool in the longitudinal direction. This is only possible if the geometry of the indexable insert - and thus the generated tool path - corresponds to the geometry of the rolling ball. Fig. 29 shows a scheme of the combined process using a conventional indexable insert (left) and a round indexable insert (right). It can be observed that, due to reasons of geometry, an insert with a corner radius of $r_{\varepsilon}=0.8 \mathrm{~mm}$ leads to a shift of the center points $(\mathrm{X} 1=1 \mathrm{~mm})$. Thus, with a feed of $\mathrm{f}_{\mathrm{w}}=\mathrm{f}=0.1 \mathrm{~mm}$, the freshly machined surface is not rolled until 10 revolutions. With a specimen diameter of $200 \mathrm{~mm}$, respectively a circumference of $628 \mathrm{~mm}$, this corresponds to a relative distance of about $\mathrm{L}=6.3 \mathrm{~m}$. If an indexable insert with a high corner radius (e.g. $\mathrm{r}_{\varepsilon}=4 \mathrm{~mm}$ ) is used, the cutting edge and the deep rolling ball can be positioned on top of each other in the peripheral direction. Therefore, round indexable inserts with a diameter above that of the rolling ball are used for the prototypic tool.

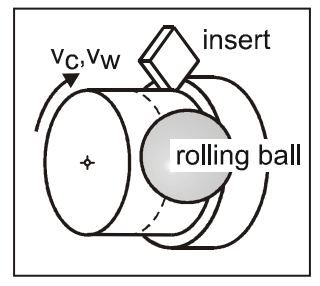

relative distance $\mathrm{L} \sim 6200 \mathrm{~mm}$

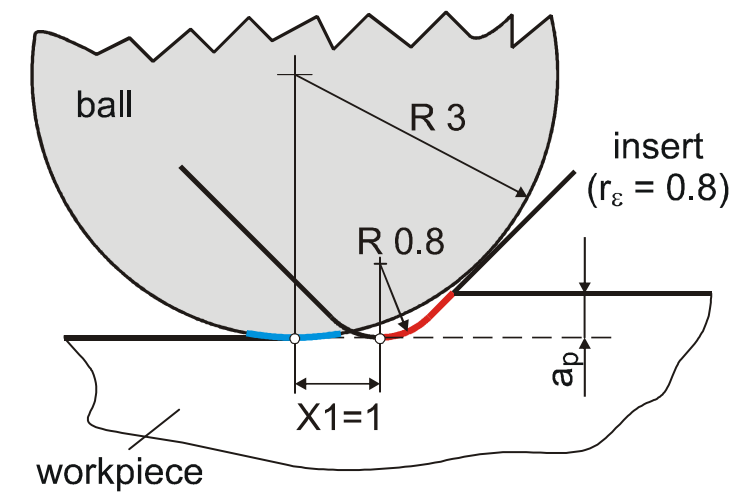

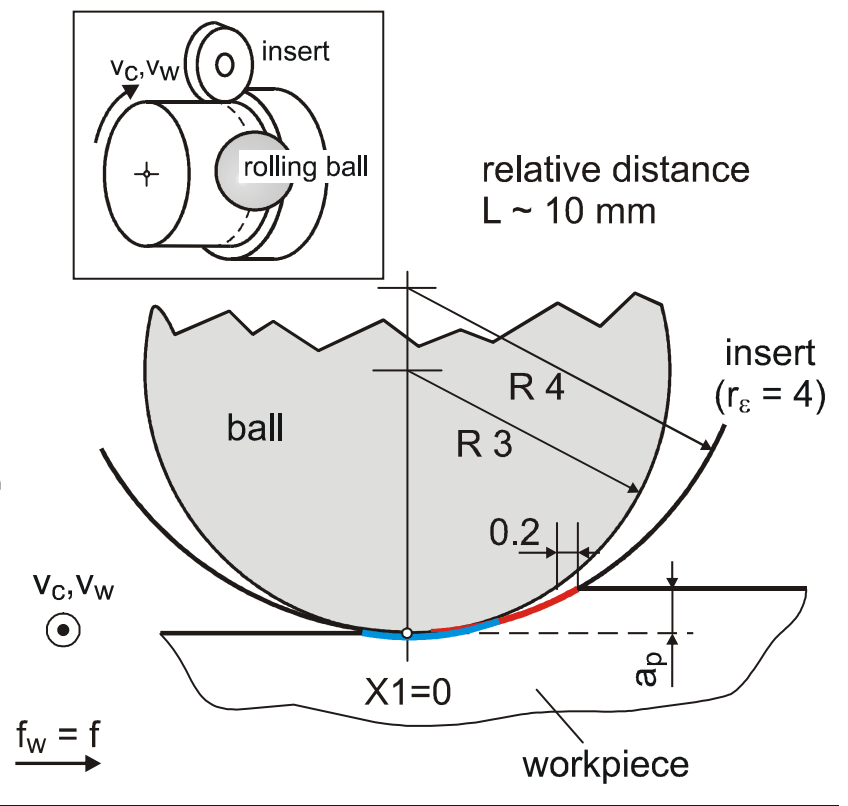
relative distance
$\sim 10 \mathrm{~mm}$

workpiece

shaft $\varnothing 200 \mathrm{~mm}$, ball $\varnothing 6 \mathrm{~mm}, \mathrm{f}_{\mathrm{w}}=\mathrm{f}=0.1 \mathrm{~mm}, \mathrm{a}_{\mathrm{p}}=0.6 \mathrm{~mm}, \mathrm{r}_{\varepsilon}=$ var.

$\mathrm{Dy} / 51660$ C IFW

Fig. 29: Influences of the geometries of the indexable insert and the rolling ball on the relative distance

\section{Development of the prototypic turn-rolling tool}

The essential challenge with regard to the design of a tool for the combined process of turning and rolling consisted in minimizing the offset between the machining and rolling part to allow the additional processing of the subsurface zone shortly after the cutting process. The prototype of the combined turning-rolling tool uses a hydrostatic deep rolling tool by the company ECOROLL of the type HG6-9R00'-SL16x16. To adjust the relative lateral position between cutting edge and rolling ball a special feature of the implemented hydrostatic deep rolling tool is exploited. The rolling ball housing is positioned with an angle of $\alpha=12^{\circ}$ to the deep rolling tool shaft. With increasing hydrostatic pressure the ball housing is elongated telescopically. This also leads to a lateral displacement of the rolling ball. This behavior is illustrated within Fig. 30. 


\section{Ecoroll HG6}

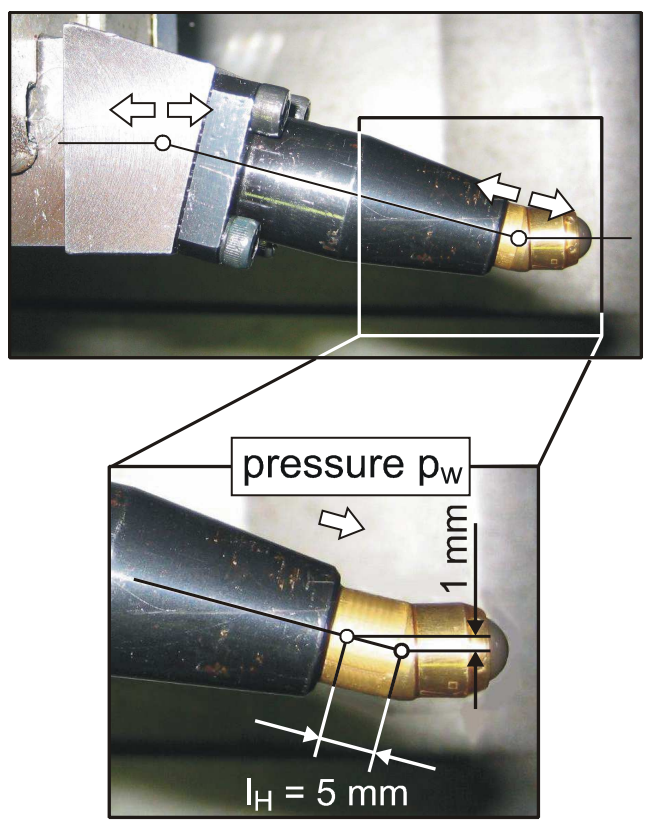

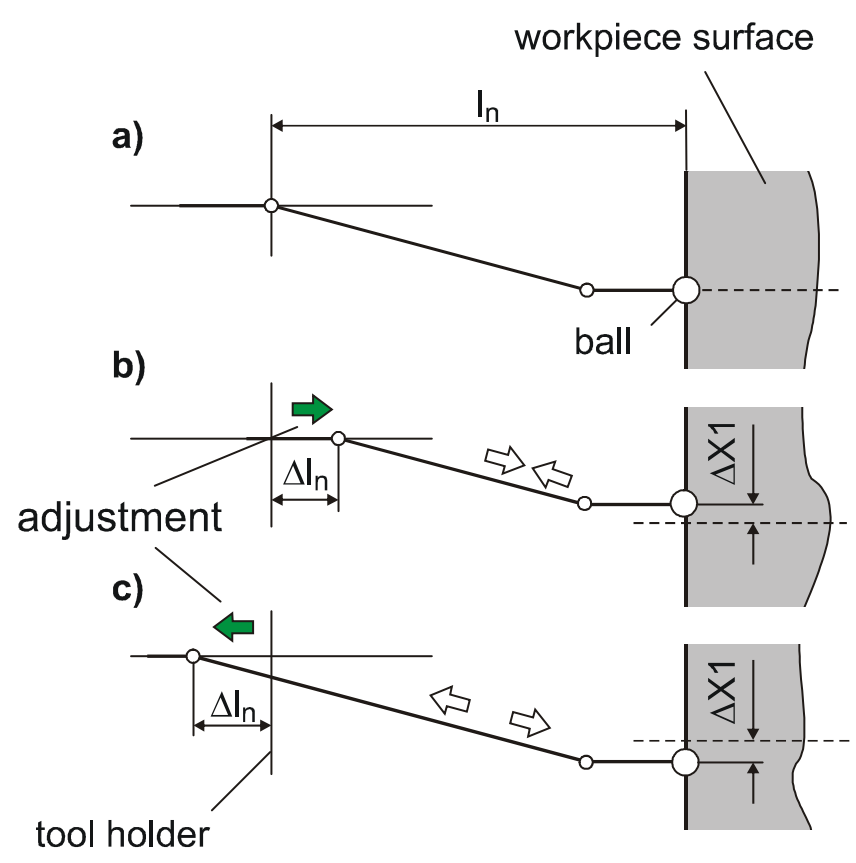

Dy/51655 @ IFW

Fig. 30: Lateral adjustment of the rolling ball

Considering these features a functional prototype with the necessary degrees of freedom is constructed with the CATIA V5 CAD software of the company Dassault Systèmes. The CAD model of the tool for the combined turning and rolling process is presented in Fig. 31.

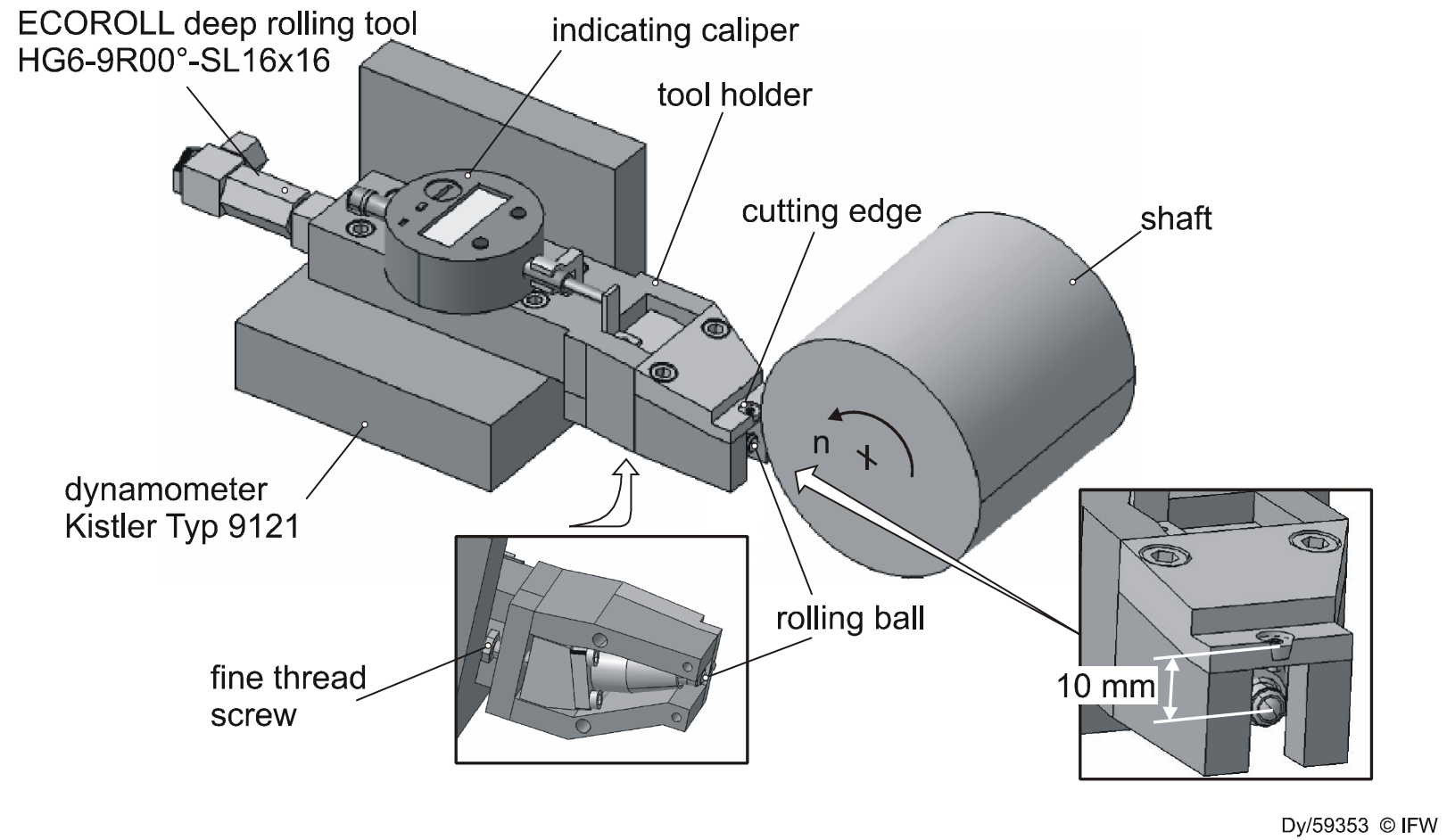

Fig. 31: CAD model of the tool for the combined turning and rolling process 
The indicating calliper is used to measure the position of the deep rolling tool, in order to determine the lateral distance between cutting edge and rolling ball. Fig. 32 shows the prototypic combined tool in the used turning center. This prototype allows simultaneous deep rolling and turning. The indexable insert and the rolling ball are positioned on top of each other with a distance of about $\mathrm{d}=10 \mathrm{~mm}$. At a cutting speed of $\mathrm{v}_{\mathrm{c}}=250 \mathrm{~m} / \mathrm{min}$, this distance is passed within $\mathrm{t}=2.4 \mathrm{~ms}$. Using this tool, both processes can be set up independently and the relative positions of the two elements to each other can be controlled during the process. Furthermore, the tool is attached to a dynamometer which measures the process forces.

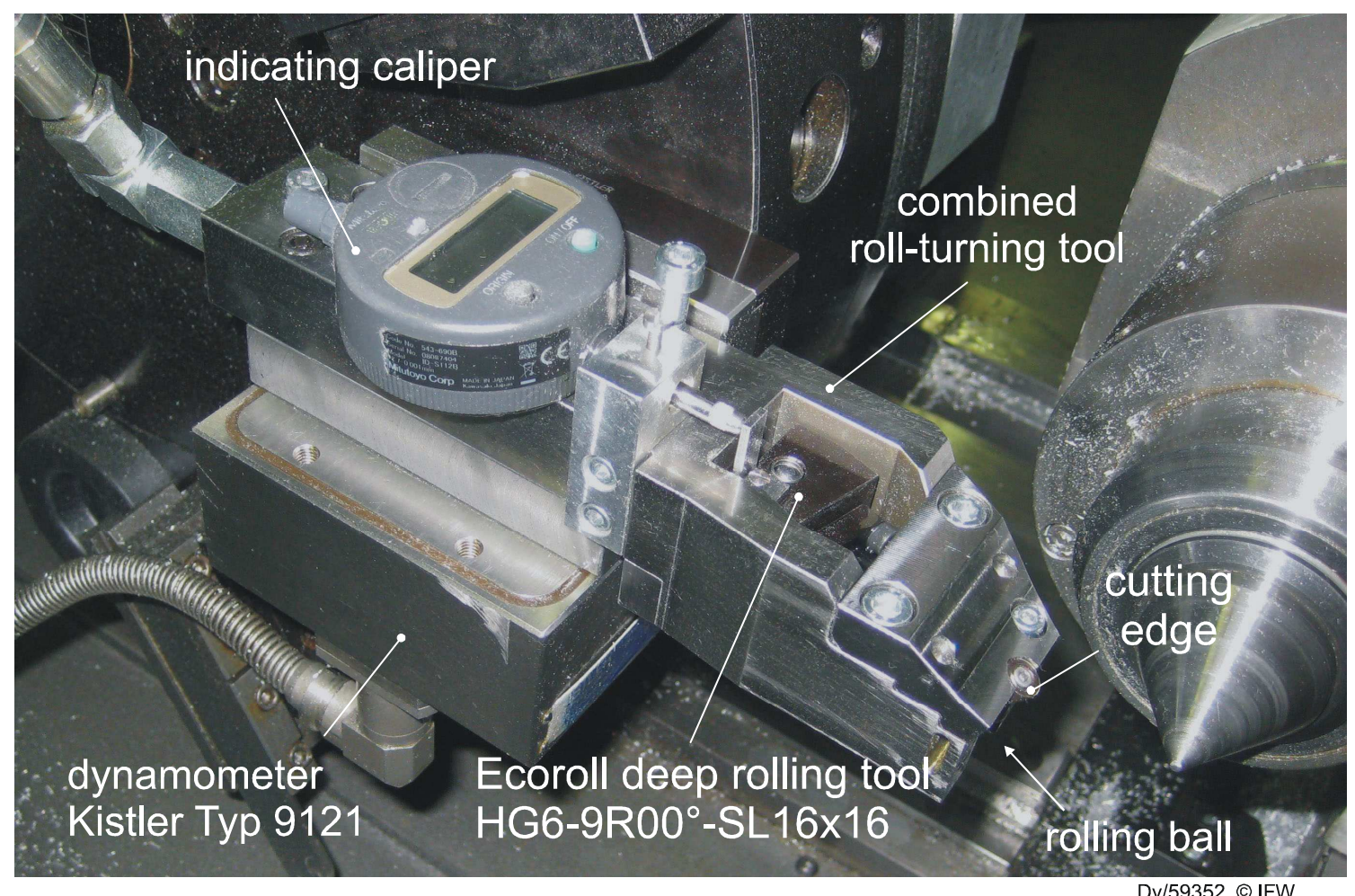

Fig. 32: The combined turning and rolling tool-prototype

\section{Application of the prototypic turn-rolling tool}

The experiments with the combined tool-prototype have been conducted at speeds of $\mathrm{v}_{\mathrm{c}}=250$ $1300 \mathrm{~m} / \mathrm{min}$. Thus the influence of a variation in the time delay between the turning process and the deep rolling process on the subsurface zone properties can be examined. Fig. 33 shows the residual stress depth distribution perpendicular and parallel to the processing direction after the separate rolling process and after the combined process of turning and rolling. 

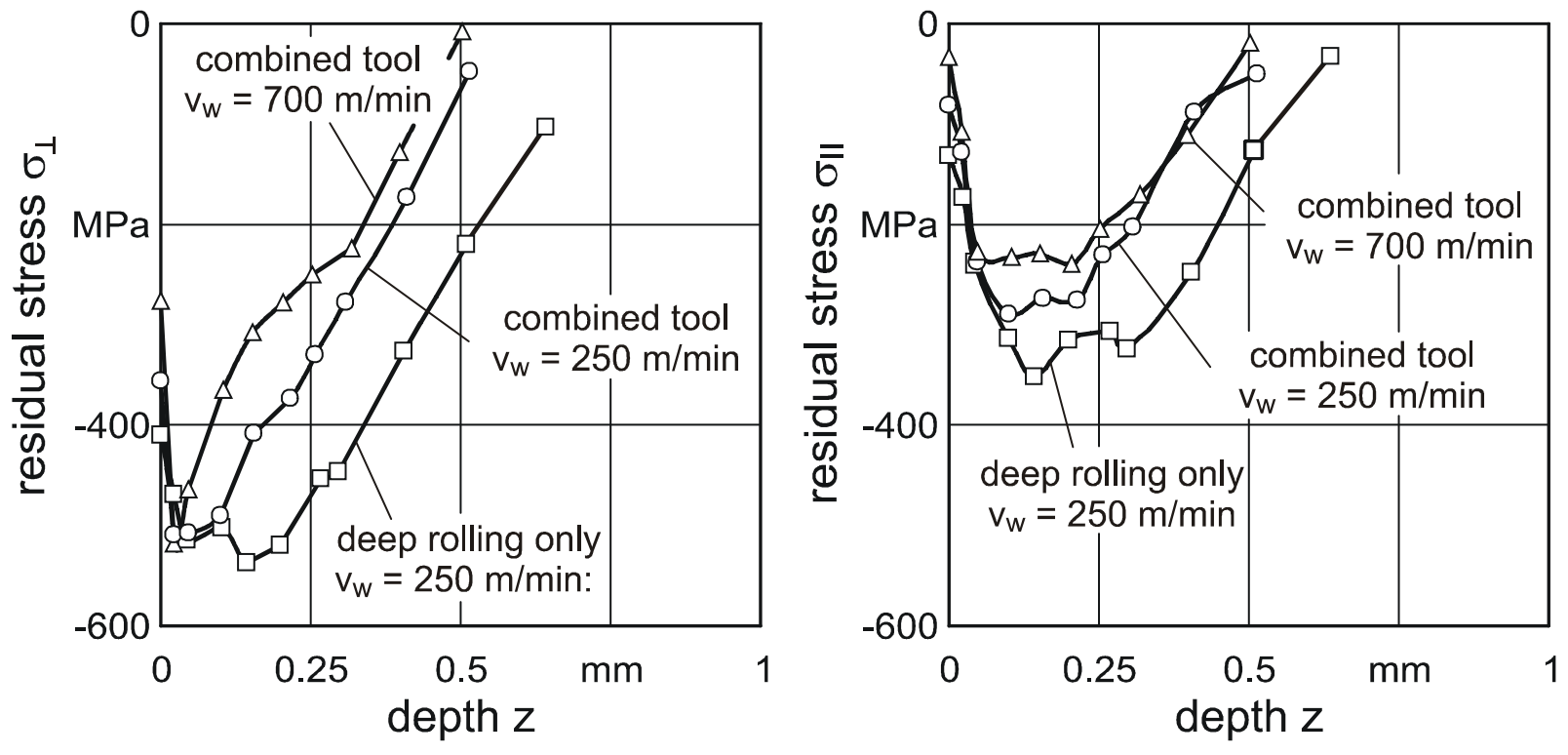

process: deep rolling

material: Al7075-T6 tool: prototype 1

HG 6 Ecoroll process parameters:

$\mathrm{f}_{\mathrm{W}}=0.129 \mathrm{~mm}, \mathrm{v}_{\mathrm{w}}=$ var.

$\mathrm{F}_{\mathrm{W}}=300 \mathrm{~N}$

Dy/59327 @ IFW

Fig. 33: Residual stress distribution resulting from the combined process

The results show that in the combined turning and rolling process at conventional speeds, the compressive residual stresses reach almost the maximum of the separate processes $(\sigma \perp<-500 \mathrm{MPa})$ within a lower penetration depth. The complete penetration depth is also slightly lower in the combined process compared to the sequential implementation of the processes. An increase in the cutting speed in the combined process enforces this effect. Besides the shift in the position of the compressive residual stress maxima, an increase in the speed also leads to a decrease in the compressive residual stresses closed the surface. This can be explained by the increased surface temperature prior to the rolling procedure due to the heat introduced by the machining operation. Presumably, the increasing softening of the workpiece areas close to the surface prevents the transmission of energy into the deeper areas of the subsurface zone.

\section{Summary and outlook}

The positive effect of the residual compressive stresses in the subsurface zone on the durability of components subjected to alternating loads has been already demonstrated by many scientists. The combined processes investigated within this subproject of the Collaborative Research Centre 675 enable the distinct modification of these stresses in the subsurface zone. The influence of the combined processes on the subsurface zone properties of aluminium components is slightly lower than of the separate and the sequential processes. This might be caused by the increased temperature level prior to the rolling procedure in the combined process. However, Scholtes et al. conducted experiments with hardened steel components which proved that the hardening of heated surfaces can have a positive effect on the durability of the components although the residual compressive stresses decrease when high temperatures occur during the hardening process [27, 28]. A similar effect can be assumed for the combined process. In order to test this thesis, fatigue tests with specimens machined in combined processes will be conducted.

The results presented in this report prove that the combined processes are generally suitable as a further development of the separate processes. The newly developed procedure and the prototypic combined tool have up to now only been designed for rotation-symmetric components. In order to treat and modify plane surfaces and, finally, free formed surfaces, the procedure has to be transferred to complex kinematics. Until now, there is no knowledge available on the effect of 
combined processes in the milling of components. Milling kinematics extend the range of possible components while also providing new opportunities for the modification of the subsurface zone. Rolling elements installed at the end face of a milling tool can be used to modify the subsurface zone of a plane workpiece on the resulting trochoidal rolling paths. Depending on the number and the eccentricity of the rolling elements, the path patterns and thus the component properties can be adjusted locally in an application-oriented manner.

\section{Literature:}

[1] Beier, E.: Gewichtskiller im Fahrzeugbau. Technica, Rupperswil, Band 54 (2005) Heft 12, pp. 22-27

[2] Peters, M.; Kayser, W. A.: Das Potential metallischer Leichtbauwerkstoffe in der Luft- und Raumfahrt. VDI-Berichte Band 1080 (1994) pp. 483-490

[3] Röttger, K.: Walzen hartgedrehter Oberflächen. Dr.-Ing. thesis, RWTH Aachen, 2003

[4] Fuchsbauer, B.: Untersuchungen zur Schwingfestigkeitsoptimierung bauteilähnlicher Proben unterschiedlicher Größe durch Festwalzen. Dr.-Ing. thesis, TH Darmstadt, 1983

Scholtes, B.; Zinn, W.: Mechanische Oberflächenbehandlung von Leichtbauwerkstoffen. In: Frieling E.; Martin, H.; Tikal, F.: Neue Ansätze für innovative

Produktionsprozesse. Kassel University Press, Kassel, 1997, pp. 376-383

Klocke, F.; Röttger, K.: Achievable part quality by hard turning in combination with hard roller burnishing. Production Engineering. Research and Development, Band 9 (2002) Heft 1, pp. 39-42

Köcher, J.: Erhöhung der Zahnflankentragfähigkeit einsatzgehärteter Zylinderräder durch Kugelstrahlen. Dr.-Ing. thesis, RWTH Aachen, 1996

F. Klocke, S. Mader: steel research int. 76 (2005), No. 2/3

Klocke, F.; Mader, S.: Fundamentals of the Deep Rolling of Compressor Blades for Turbo Aircraft Engines. steel research international 76 (2005) No. 2/3

Gregory, J. K.; Müller C.; Wagner, L.: Bevorzugte Randschichtaushärtung: Neue Verfahren zur Verbesserung des Dauerschwingverhaltens mechanisch belasteter Bauteile. Metall - Internationale Zeitschrift für Technik und Wirtschaft, Band 47 (1993) Heft 10, pp. 915-919

Kurth, B.; Bomas, H.; Mayr, P.: Einfluß der Oberflächenbeschaffenheit auf die Schwingfestigkeit von Aluminium-Druckguß. Mat.-wiss. u. Werkstofftechnik 26 (1995), pp. 101-110

[15] Altenberger, I.; Nikitin, I.: HTM, vol. 59 (2004), pp. 269-275

[16] El-Axir, M.H.; El-Khabeery, M.M.: International Journal of Machine Tools and Manufacture, vol. 41 (2001), pp. 1705-1719

Spur, G., Uhlmann, E., Elbing, F., Hühns T.: Konferenzbericht Oberflächentage, Mehrländertagung, Freiburg (2002), pp. 57-62

Wagner, L.; Berg, A.; Dörr, T.; Hilpert, M.: Mechanische Oberflächenbehandlungen. Grundlagen - Bauteileigenschaften - Anwendungen, DGM (2000)

VDI/VDE Richtlinie 2032, Rollieren und Festwalzen (1975)

El-Axir, M.H.; El-Khabeery, M.M.: Journal of Materials Processing Technology, vol. 132 (2003), pp. 82-89 
[18] Hassan, A.M.; Abd Al-Wahhab, O.M.: Materials and Manufacturing Processes, vol. 13 No. 4 (1998), pp. 505-515

[19] Wagner, L.: Materials Science and Engineering, vol. A 263 (1999), pp. 210-216

[20] Özdemir, A.T.; Hermann, R.: Journal of Materials Science, vol. 34 (1999), pp. 12431252

[21] Hassan, A.M.; Maqableh, A.M.: Journal of Materials Processing Technology, vol. 102 (2000), pp. 115-121

[22] Tönshoff, H.K.; Schmidt, J.; Winkler, J.: Technica, vol. 3 (1997), pp. 13-21

[22] Tönshoff, H.K.;. Karpuschewski, B.; Winkler, J.: Metall IDR, vol. 31 no. 4 (1997), pp. 357-364

[23] Denkena, B; Schnadt-Kirschner, B.; Groppe, M.: Neue Fertigungstechnologien für die Luft- und Raumfahrt, Hannover (2003)

[24] Tönshoff, H.K., Karpuschewski, B.;. Schmidt, J., Andrae, P.: Seminar Aluminium im Maschinenbau, Düsseldorf (1998)

[25] Denkena, B.; Becker, J.C.; Gey, C.; Boehnke, D.; de León García, L.: Proceedings of the 4th International Conference „THE Coatings“, Erlangen (2004)

[26] Denkena, B.; Weinert, K.; Alpers, P.; Hammer, N.: Annals of the German Academic Society for Production Engineering, XIII, (2006), pp. 1-4

[27] A. Cherif, B. Scholtes: Kombinierte thermische und mechanische

Festwalzbehandlungen von gehärtetem und vergütetem Stahl Ck45. Journal of Heat Treatment and Materials 03/2008, pp. 155-161

[28] I. Nikitin, I. Altenberger, M. A. Cherif, P. Juijerm, H. J. Maier, B. Scholtes: Festwalzen bei erhöhten Temperaturen zur Steigerung der Schwingfestigkeit. Z. Werkst. Wärmebeh. Fertigung 61 (2006) 6, pp. 289-295 